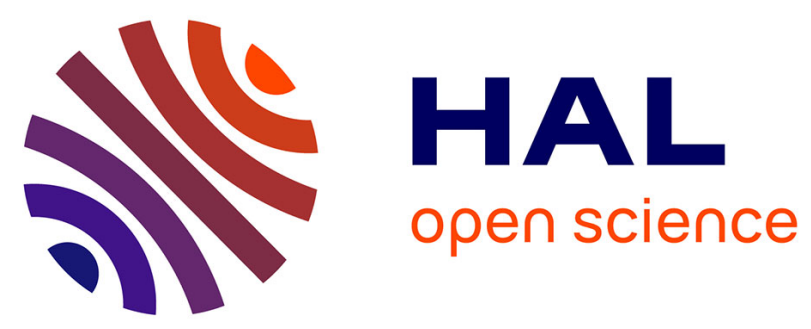

\title{
Tolerancing: Managing uncertainty from conceptual design to final product
}

Edward Morse, Jean-Yves Dantan, Nabil Anwer, Rikard Söderberg, Giovanni Moroni, Ahmed Qureshi, Xiangqian Jiang, Luc Mathieu

\section{- To cite this version:}

Edward Morse, Jean-Yves Dantan, Nabil Anwer, Rikard Söderberg, Giovanni Moroni, et al.. Tolerancing: Managing uncertainty from conceptual design to final product. CIRP Annals - Manufacturing Technology, 2018, 67 (2), pp.695-717. 10.1016/j.cirp.2018.05.009 . hal-01940533

\section{HAL Id: hal-01940533 \\ https://hal.science/hal-01940533}

Submitted on 30 Nov 2018

HAL is a multi-disciplinary open access archive for the deposit and dissemination of scientific research documents, whether they are published or not. The documents may come from teaching and research institutions in France or abroad, or from public or private research centers.
L'archive ouverte pluridisciplinaire HAL, est destinée au dépôt et à la diffusion de documents scientifiques de niveau recherche, publiés ou non, émanant des établissements d'enseignement et de recherche français ou étrangers, des laboratoires publics ou privés. 


\title{
Tolerancing: Managing uncertainty from conceptual design to final product
}

\author{
Edward Morse (3) ${ }^{\mathrm{a}, *}$, Jean-Yves Dantan $(2)^{\mathrm{b}}$, Nabil Anwer $(2)^{\mathrm{c}}$, Rikard Söderberg $(2)^{\mathrm{d}}$, \\ Giovanni Moroni (2) $)^{\mathrm{e}}$, Ahmed Qureshi ${ }^{\mathrm{f}}$, Xiangqian Jiang (1) ${ }^{\mathrm{g}}$, Luc Mathieu (1) \\ a University of North Carolina at Charlotte, 9201 University City Blvd, Charlotte, NC 28223, USA \\ b École Nationale Supérieure d'Arts et Métiers, 4, rue Augustin Fresnel, Metz Technopole, 57078 Metz Cedex 3, France \\ ${ }^{\mathrm{c}}$ LURPA, ENS Paris-Saclay, Université Paris Sud, Université Paris-Saclay, 94230 Cachan, France \\ ${ }^{\mathrm{d}}$ Chalmers University of Technology, 41296 Göteborg, Sweden \\ e Politecnico Milano, via La Masa 1, 20156 Milano, Italy \\ ${ }^{\mathrm{f}}$ University of Alberta 116 St. and 85 Ave., Edmonton, AB T6G 2R3, Canada \\ ${ }^{\mathrm{g}}$ University of Huddersfield, Queensgate, Huddersfield, England HD1 3DH, United Kingdom
}

\begin{abstract}
A B S T R A C T
Variability is unavoidable in the realization of products. While design must specify ideal geometry, it shall also describe limits of variability (tolerances) that must be met in order to maintain proper product function. Although tolerancing is a mature field, new manufacturing processes and design methodologies are creating new avenues of research, and modelling standards must also evolve to support these processes. In addition, the study of uncertainty has produced widely-accepted methods of quantifying variability, and modern tolerancing tools should support these methods. The challenges introduced by new processes and design methodologies continue to make tolerancing research a fertile and productive
\end{abstract} area.

\section{Introduction}

Uncertainty is ubiquitous in any engineering system, at all stages of product development and throughout the product life cycle. This presence of uncertainty incurs risks - to the product performance, to process scheduling, to market acceptance, or to the business itself. To mitigate these risks, strategies that bound design variables and their associated uncertainty are employed. These related concepts-uncertainty, risk, and tolerances-create the landscape within which many engineering design activities are performed. In the classic geometrical domain, uncertainty appears as dimensional variability, risk relates to non-conformance, and tolerances are used to limit the allowable variability.

The rising demand for high reliability, robustness and safety of complex engineering systems, such as automobiles and aircraft, requires engineers to understand and manage various uncertainties during the design process. Such uncertainties include anticipated manufacturing variation, imperfect numerical approximations, imprecise estimates of loading, and limited prototypes on which to perform testing. These uncertainties, if incorrectly managed, could lead to significant design bias, costly maintenance, even catastrophic consequences, especially for multidisciplinary systems. Therefore, it has become imperative to identify the sources of uncertainty and quantify the impact of multiple types of uncertainties in multidisciplinary systems design [12,225,248,293,294].

Examples of uncertainty include manufacturing imprecision, variations in product usage, and geometric variability; all of these are subject to imperfections and incomplete information. Such uncertainty has a significant impact on product performance. The ability to evaluate and improve product performance where several types of uncertainty are present is very important to avoid warranty returns and scraps [60].

V. Srinivasan identified two axioms underlying his discussion of computational metrology [280,281]. These are:

1) The axiom of manufacturing imprecision: "All manufacturing processes are inherently imprecise and produce parts that vary."

2) The axiom of measurement uncertainty: "No measurement can be absolutely accurate and with every measurement there is some finite uncertainty about the measured attribute or measured value."

Due to the imprecision associated with manufacturing process; it is not possible to repeatably produce the product's theoretical dimensions. This results in a degradation of the product performance. In order to ensure the desired behavior and the 
performance of the engineering system in spite of uncertainty, the component features are assigned tolerance limits within which the characteristic of the feature - i.e. situation and intrinsic characteristic - lies. This activity is referred to as "tolerancing". Further, the inability to determine the true value of actual part characteristics influences the ability to properly characterize manufacturing processes. To manage the rate of out-tolerance products and to evaluate the impact of component tolerances on product performance, designers need to simulate the influences of uncertainty with respect to the functional requirements.

\subsection{History of tolerancing}

The development of tolerancing can be traced back to the end of the 19th century or the beginning of the 20th century through the need for more precisely engineered components to be assembled interchangeably $[99,47,131,240]$. Since 1905 , the "Taylor Principle" or "envelope requirement" which is based on the hard gauging practice, allowed the development of a function-oriented approach for assembly, thus enabling the foundations for a scientific approach to tolerancing [287]. Subsequently, the military and manufacturing sectors encouraged the development of standards addressing limits and fits, technical drawings, subcontracting documents, and also gave more consideration to manufacturing operations and the control of workpiece variability in the practices of the design and engineering offices [130].

A geometric model for tolerancing was developed by S. Parker in 1938 through the development of tolerances of location and tolerance zones [230]. Parker's work is seen as the foundation of geometric tolerancing and has paved the way for new concepts such as the principle of the maximum material condition developed by Chevrolet in 1940 [64]. At the same time, efforts to standardize the graphical symbolism of tolerancing for technical drawing led to the GD\&T (Geometric Dimensioning and Tolerancing) system through the development of American standards MIL-STD-8 (1949), ASA-Y14.5 (1957), USASI Y14.5 (1966), ANSI Y14.5 (1973), ANSI Y14.5M (1982), ASME Y14.5M (1994) [27], and ASME Y14.5 (2009) [24]. Similarly, international tolerancing standards (ISO) have also evolved from the ISO system of limits and fits ISO/R 286 (1962) and standards for technical drawing and geometrical tolerancing ISO/R 1101 (1969) to a new system of standards for Geometrical Product Specifications (GPS) which are now being developed in the different working groups of 1SO/TC 213 [222].

The work in TC 213 is based on the idea that the field of geometrical product specifications can be described as a matrix: the rows are the various requirements and the columns are the various pieces that have to be in place to create an unambiguous specification. In this new approach, specifications are defined by an ordered set of operations, each of which is applied to a feature [167] according to Mathieu and Ballu [208], based on these ordered set of operations (or operators) the uncertainties links to tolerancing activities are developed in [169]. The idea of the GPS system is to guarantee and ensure mechanical product properties in terms of functionality, reliability and interchangeability.

Over the last 40 years, the confluence of industrial need, the rise of the CAx software, and the development of coordinate metrology has justified both significant research and an evolution of the tolerancing standards. The CIRP Seminar on Computer Aided Tolerancing (CAT) was conceived during the 1980s following the growing desire of the CIRP community to undertake cooperative projects on the topics of tolerancing and dimensioning of mechanical parts, the functional meaning of tolerances, uncertainty and standardization [132,232,314]. Two main needs were identified to be emerging at that time [313]: the integration of tolerancing procedures in the CAD/CAM environment, and the assessment of geometrical errors of Coordinate Measuring Machines (CMMs) and algorithms for analyzing workpiece data.
These two areas were being researched extensively with most of those contributions being published at the CIRP Annals [241]. Meanwhile, in the field of Computer Aided Process Planning (CAPP), tolerance transfer and tolerance charting were being computerized in order to be integrated into CAD/CAM systems $[115,117]$. Bearing in mind the relevance that CAT was acquiring, the necessity to meet, share and discuss the developments of this field was manifest. In December 1989, in response to this need, Prof. R. D. Weill organized the first two-day Working Seminar on CAT in Jerusalem, Israel. Since then, the seminar has been held every two years, taking place 15 times worldwide and with over 600 papers published.

\subsection{New challenges in tolerancing}

The introduction of new manufacturing technologies has broadened the scope of both geometry and material attributes that a designer may specify. With this specification naturally comes the need for control of variability in these new attributes. As an example, new additive manufacturing processes can produce assemblies in as-built form, create complex lattice structures for support, and produce gradients in the density and composition of material throughout the workpiece. These potential workpiece attributes introduce challenges in the modelling of the workpiece's nominal design, and until the nominal properties are defined, variability in these attributes is difficult to control. For example, consider the complex support structure in Fig. 1: both the explicit modelling of this geometry, and appropriate controls to the support shapes represent challenges to conventional tools and practice. However, there is a great opportunity to simultaneously consider control methods as the modelling methods are developed. If a particular representation is chosen to describe how material density changes throughout a part, this representation should accommodate the allowable variation in this density attribute.

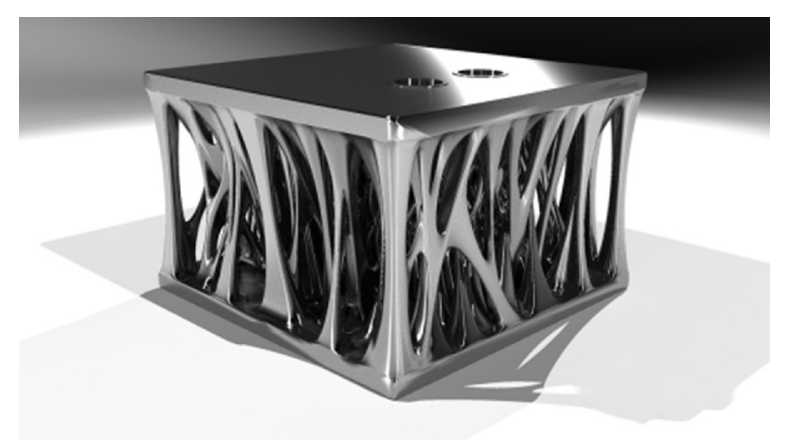

Fig. 1. Complex support structure.

In addition to broadening the domain of workpiece specification, the consistency and traceability of data throughout the product lifecycle is of increasing importance as enterprises rely more heavily on a digital representation of not only the workpiece, but the processes that produce, inspect, and maintain the product through-out its lifecycle. Current standards describe how the tolerances associated with features may be presented to a human user, as shown in Fig. 2, but do not require a specific underlying model or representation. The concept of a "digital thread" is that all product information is captured in a format that is usable by the design, manufacturing, and inspection activities of the product's lifecycle, and that the information is uniquely identifiable, so that the traceability of information may be maintained.

These new challenges (and others) are revisited in more detail in Chapter 7, where a framework for future research is proposed in the context of the information provided in the intervening Chapters. 


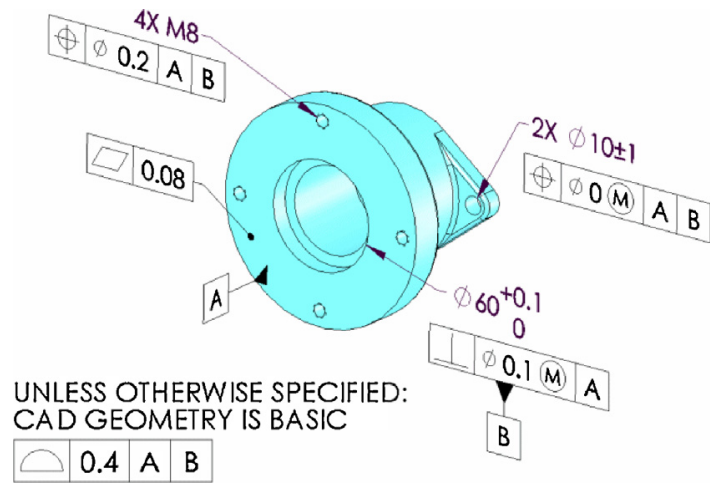

Fig. 2. Example of model presentation to the user.

\subsection{Extensions to tolerancing}

The concept of tolerance is similar to the concept of margin, with the main difference being that these concepts are used in different fields. The term "engineering tolerance" refers to the permissible limit or limits of variation in a physical dimension or in a physical property of a material, while a margin may refer to model parameters in a variety of situations.

Quantification of Margins and Uncertainty (QMU) [225,226] focuses on the identification and analysis of performances and their margins that are evaluated under uncertainties using computational modelling and simulation. QMU focuses on rigorously quantifying model uncertainty in order to support comparison to design margins, and evaluate their impacts on the response output variables. There is currently no standardized methodology across the simulation community for conducting QMU.

\subsection{Subsequent chapters}

There are many different approaches to manage uncertainties which are closely interrelated with tolerancing. The remainder of this paper is organized as follows: Chapter 2 contains a review of uncertainty taxonomies, and this language is used throughout the following chapters; Chapter 3 describes how these uncertainties are relevant to the different stages of the product design process. The unambiguous specification of tolerances requires a standardized language for communication (Chapter 4). Techniques to propagate and analyze the tolerances are described in Chapter 5, and methods to allocate the tolerances are covered in Chapter 6. New challenges foreseen in the field of tolerancing are discussed in Chapter 7, with conclusions and a structure to guide future work in Chapter 8.

\section{Uncertainty taxonomy}

In this chapter, a general view of the uncertainty concept is provided. Relevant papers in the domain of uncertainty classification, design under uncertainty, uncertainty, and tolerancing are reviewed. Definition of uncertainty is widely different and is greatly influenced by context and discipline.

One of the most controversial discussions in uncertainty analysis relates to the classification of uncertainty into several types and of possible sources of uncertainty. A classical classification is the separation of uncertainty into the two types: aleatory and epistemic. Aleatory uncertainty, also referred to as irreducible, objective or stochastic uncertainty, describes the intrinsic variability associated with a physical system or environment [35]. According to the probability theory, aleatory uncertainty is modelled by random variables or stochastic processes. Epistemic uncertainty, on the other hand, is due to an incomplete knowledge about a physical system or environment. The definitions of uncertainty are briefly explained through Section 2.1. Afterward, uncertainty taxonomies are provided in Section 2.2.

\subsection{Concept of uncertainty}

Uncertainty is ubiquitous in engineering design. As we aim for designing more and more complicated systems, current tools are not capable of accurately predicting the behavior and design parameters of the designed systems. This inability, which can be due to various reasons, is discussed as "uncertainty" in design. Lack of knowledge about a system and its environment, imperfect manufacturing, coupling of a system's elements, errors and many other issues cause the design to be uncertain. The concept of uncertainty is discussed and classified in different engineering domains such as systems engineering [183], civil engineering [28], structural engineering [211], aerospace [88] and mechanical engineering [228].

The term 'uncertainty' has come to encompass a multiplicity of concepts. Basic definitions of uncertainty include "liability to chance or accident", “doubtfulness or vagueness", "want of assurance or confidence; hesitation, irresolution", and "something not definitely known or knowable".

Uncertainties are things that are not known, known only imprecisely, or incompletely. There is no value judgment in stating that something is uncertain - it may be worse or better than expected.

In the field of production engineering, the concept of uncertainty is associated with precision and metrology. Uncertainties are factual and measurable; things are known, or not known, or known to a quantifiable degree or within quantifiable bounds. Measurement results are affected by measurement uncertainty, which leads to technical and economic risks in industrial companies. By assessing the risks and the connected consequences of the decisions (conformity verification), the significance of the measurement result can be evaluated $[303,304]$. The simulations of the functional chain of conformity assessments generate an estimation of the significance of measurements in dependence of measurement uncertainty and other types of uncertainties. This notion of uncertainty is by now well entrenched in metrology.

Uncertainty is present in all areas of design, manufacturing and metrology. ISO GPS standards established the duality principle of specification and verification and that uncertainty develops through the product lifecycle. In ISO/TS 17450-2, the concept of uncertainty is expanded to specification and verification. The uncertainties through the product life cycle span from the design intent to the uncertainty in the performance of the product as well as the environment in which it will perform. The classification is provided in Fig. 3. The uncertainty is divided into correlation uncertainty and compliance uncertainty, which comprises specification uncertainty and measurement uncertainty:

- Correlation uncertainty is a measure of how well the functional requirements correlate to product specifications. If there is a good correlation between the functional requirements and the specification, then the correlation uncertainty is low.

- Compliance uncertainty is the sum of specification uncertainty and measurement uncertainty, with which it can be proven that a workpiece complies with all possible interpretation of a specification.

- The specification uncertainty characterizes the ambiguity in the specification expression. It is caused by poor definitions in standards and other requirement documents [200].

- The measurement uncertainty is considered by the metrologists and well described in GUM. The measurement uncertainty includes all the causes of variation of the quantity intended to be measured, usually through inspection. The computation method of measurement uncertainty is given in GUM [134] and simplified in ISO 14253-2 [166]. 
- The combination of the measurement uncertainty, the specification uncertainty and the correlation uncertainty is called "total uncertainty".

It can be seen that even with a low uncertainty in measurement, the total uncertainty could be very significant when correlation and/or specification uncertainties are large.

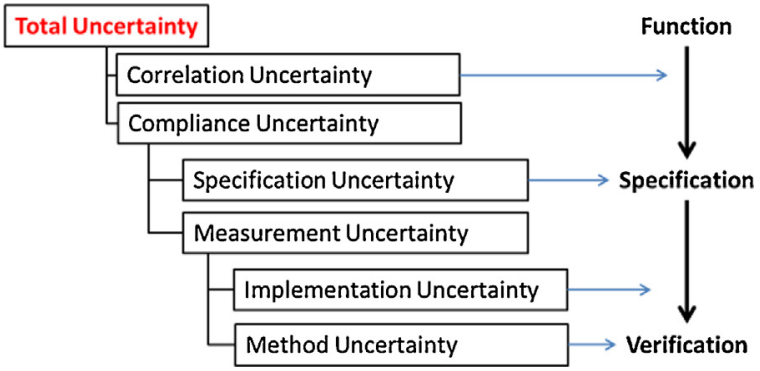

Fig. 3. GPS uncertainty taxonomy

\subsection{Correlation uncertainty}

The correlation uncertainty aims to ascertain the appropriateness of the geometrical product specifications to guarantee the functional requirements. It is the designer's responsibility to keep the correlation uncertainty as low as possible by the correct expression of the intended functional requirements. In the actual ISO GPS standards, the "correlation uncertainty" is replaced by the "ambiguity of the description of the function" [169] which refers to the "uncertainty arising from the difference between the actual specification operator and the functional operator that defines the intended function of the workpiece".

Functions such as the assembly of parts can be completely described by ISO GPS and ASME Y14.5 standards, and so the correlation uncertainty is then considered to be low [140]. However, some functions are very complex and depend not only on the geometry described by the shape, the size and the texture, but also by the material properties, the manufacturing methods, and the operating conditions and many simplifying assumptions must be made. This difficulty is described in Refs. [236] and [177] as "perhaps the biggest inverse problem in manufacturing" and also by Srinivasan [280], stating "Correlation uncertainty, in particular, is an uncharted territory. Standards do not tell us how to find this."

Only few research addressed correlation uncertainty. Dantan et al. [73] developed an approach for the expression and evaluation of the correlation uncertainty for gear conformity. Weckenman and Hartman [311] proposed a function-oriented method based on mathematical-physical model of the function, and integrated this with the entire process chain for the micro-structured surfaces of an inking roll. To accommodate the correlation uncertainty, Jiang and Whitehouse [177,316] pointed out that the functional performance should be basically classified and new technological shifts should be addressed. The characterization of function and the correlation with geometric parameters have been intensively investigated in the domain of micro-geometry and surfaces using function maps that permits also to consider the manufacturing process with only few parameters to correlate the function and to avoid contributing to "the parameter rash" [315].

The shift towards micro-parts, freeform and structured surfaces for added-value manufacturing, and the optimization of the performance of the products represent new challenges in modern design when tackling correlation uncertainty. Functionalities of such freeform and structured surfaces can be clearly defined in the first place, such that the functionalities can be directly interpreted into specifications to define the surfaces. It is envisaged that in such cases, correlation uncertainty can be characterized mathe- matically and then be reduced significantly. Whilst design for additive manufacturing (AM) is genuinely function-oriented, the challenges associated with AM specifications with consideration of correlation uncertainty are still emerging (see Section 7.1). New interdisciplinary approaches to correlate the geometry at multiple scales and the function and the efficient integration between design, manufacturing and metrology are recently explored with promising results [289].

\subsection{Uncertainty taxonomy}

A significant amount of research has been devoted to the definition and classification of the uncertainty. We will consider uncertainties from the point of view of the designer.

The analysis of this paper is mainly based on the classical taxonomy with considering the categorization of Thunnissen [294]. With basis of aleatory and epistemic uncertainties, Thunnissen added two more categories: ambiguity and Interaction. This structure is shown in Fig. 4, and each of the uncertainty categories is discussed in the paragraphs that follow.

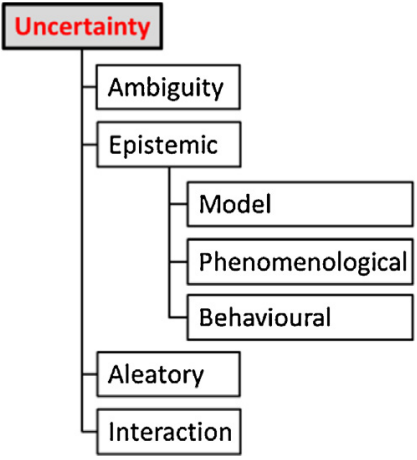

Fig. 4. Thunnissen's uncertainty taxonomy.

Ambiguity has also been called imprecision, design imprecision, linguistic imprecision, and vagueness. Although it can be reduced by linguistic conventions and careful definitions, ambiguity remains an unavoidable aspect of human discourse. In the context of tolerancing, the specification uncertainty is similar to the ambiguity. This point will be detailed in the Chapter 4 , where standards play an important role.

Epistemic uncertainty is any lack of knowledge. The key feature is that the fundamental cause is incomplete information or incomplete knowledge of some characteristic of the system or the environment. Thunnissen [294] classified epistemic uncertainty into Model, phenomenological and behavioral uncertainty:

- Model uncertainty is in the accuracy of the model of a system regarding the actual system. In other words, it is the difference between the mathematical model and the actual behavior of the system. Since the approach is to model the system; model uncertainty is an important type of epistemic uncertainty here. Some of the most difficult problems arise from unintended omissions from the model - these can be thought of as the "unknown unknowns." Model uncertainty can also be due to approximation errors, programming errors or numerical errors. - Phenomenological uncertainty is related to the behavior of a system in different conditions. It can be due to unknown impacts of the environment, unimaginable behavior of the system in specific condition, or possible behavior of the system while using specific design technique. It may also be due to limited understanding of the behavior of key parameters of the phenomenon or their interactions. To model a system, it is necessary to predict its behavior. Therefore, considering phenomenological uncertainty is essential. This type of uncertainty is mostly in qualitative form (related to the system's 
function) though it is important to consider this type of uncertainty in modelling and designing the structure of the system. So, for the elicitation of this type of uncertainty the designer needs a model that creates the link between function and physical structure.

- Behavioral uncertainty is related to the uncertain individual or organizational behavior. It can be due to the design decisions that are made during the design process, customer or stake holder requirement uncertainty, uncertainty in future action of the user or organization while interacting with the system, or human errors during development of a system.

In the context of tolerancing, the variability analysis is affected by these uncertainties. In fact, variability analysis includes variability modelling, system behavior modelling and variability propagation. This point will be detailed in the Chapter 5 .

Aleatory uncertainty is inherent variation associated with a physical system or environment under consideration. Aleatory uncertainty goes by many names: variability, irreducible uncertainty, inherent uncertainty, or stochastic uncertainty. In the context of tolerancing, this uncertainty is the most well-known [71].

Interaction uncertainty arises from unanticipated interaction of many factors and/or disciplines, each of which might, in principle, be or should have been foreseeable. Potential techniques to deal with this type of uncertainty are simulation, multidisciplinary design optimization (MDO), and complexity science. In the context of tolerancing, this uncertainty affects the tolerance allocation (Chapter 6).

Although this paper will focus on Thunnissen's classification, there are other classifications for uncertainty [87,184] in design and modelling that need to be mentioned as well. Walter et al. [302] has another categorization with focusing on modelling and simulation. They categorized uncertainty into "phenomenological uncertainty", "uncertainty in human behavior", "uncertainty in data" and "uncertainty in model and simulation" (shown in Fig. 5). In comparison to Thunnissen's classification, phenomenological uncertainty and uncertainty in human behavior are epistemic uncertainties in the sub-category of phenomenological and behavioral uncertainties respectively. Uncertainty in data can be due to its variation, which in this case is aleatory uncertainty, or due to the vagueness, which in this case is epistemic uncertainty [302]. Model and simulation uncertainty in this categorization can be in the concept (epistemic-phenomenological), the mathematical model (epistemic-model), programming (epistemic-behavioral) or visualization of effect (aleatory). Structural engineering follows a somewhat analogous classification [211].

\begin{tabular}{|l|l|}
\hline Uncertainty \\
\hline Uncertainty in human behaviour \\
Uncertainty in data \\
\hline Uncertainty in model and simulation \\
\hline
\end{tabular}

Fig. 5. Walter's uncertainty taxonomy.

Engelhardt et al. [104] categorizes uncertainty into three types, as shown in Fig. 6:

1) Stochastic uncertainties: these are related to the probability and propagation of an event. They are also related to the uncertain values for entities in design. This is aleatory uncertainty in the Thunnissen's classification.

2) Unknown uncertainties: This is regarding the lack of knowledge about an event, effect or behavior of a system. This is an epistemic uncertainty.

3) Estimated uncertainty: This uncertainty is when the effect is known but the probability of the event is partially quantified.
This represents a case where both aleatory and epistemic uncertainties exist.

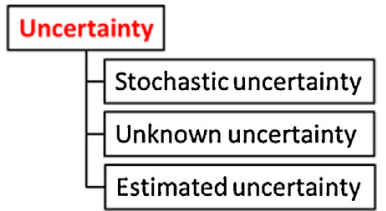

Fig. 6. Engelhardt's uncertainty taxonomy [104].

\subsection{Observations}

This chapter summarizes uncertainty taxonomies and definitions in the fields of precision engineering and product design. The classification the is used separates uncertainty into four types: ambiguity, epistemic, aleatory, and interaction. Epistemic uncertainty is further broken out into model, phenomenological, and behavioral uncertainty.

The next chapter provides the position of the uncertainty management in the context of Product design.

\section{Uncertainty management in design}

Engineering Design problems are 'ill-defined' problems [100]. In new product development (NPD) processes, the numbers of unknowns far outweigh the number of knowns. This results in a process that has a high degree of uncertainty at the start, which is progressively reduced through co-evolution of product specification and product design as the process progresses. In practice, NPD processes generally follow a divergent convergent pattern with stage-gated project process flow allowing for progressive design and development maturity [238]. This characteristic divergent convergent pattern enables the designer to deduce and reduce the uncertainty throughout the process by narrowing the choices towards feasible solutions throughout the process. The design state, which is defined as the incorporation of all the information about a design as it evolves, also progressively transitions from being abstract (text descriptions, customer requirements), to concrete (analytical models, controlled geometric representation, firm specifications) $[227,324,325]$.

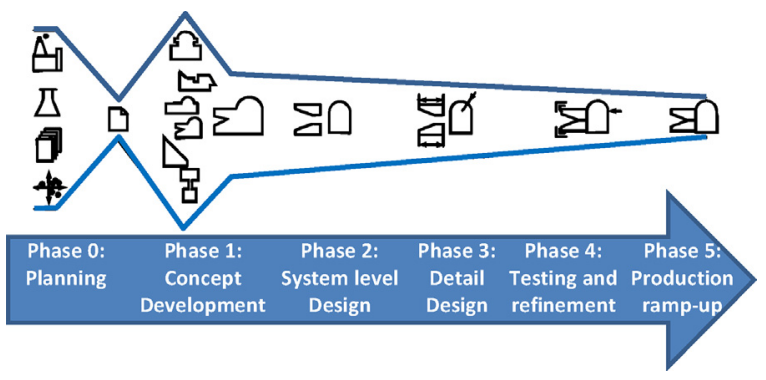

Fig. 7. Generic product development process according to Ulrich and Eppinger [105].

Using the uncertainty taxonomy described in the previous section, and considering the 6 phases of a generic design process [105] shown in Fig. 7, the types of uncertainty and their impact in each phase can be identified. Each design phase is described in the paragraphs that follow, and summarized in Fig. 8.

0. Planning: In this phase, the design state is in its most abstract form. The design space is also at the point of being least explored. Consequently, this phase is characterized by a high degree of ambiguity and a significant degree of epistemic and interaction uncertainty. Due to the abstract nature of the design state, the aleatory uncertainty cannot be well defined in this phase. 
1. Concept development: This is a critical divergent-convergent phase of the NPD process. In this phase, possible concepts to the design problem are determined. This phase is characterized by a reducing ambiguity as the design state evolves along with the co-evolution of design problem and solution. This leads to a high level inclusion of interaction uncertainty as different interactions between the elements of the system as well as the interaction of the system with the different stakeholders (environment, users, ... ) is considered. Epistemic uncertainty in designer's decisions toward identifying a solution is unavoidable.

2. System-level design: The concept obtained in the previous phase is fixed and system level decisions are made in this phase. This phase is characterized by reducing ambiguity as the key product decisions are agreed upon, enabling the designers to finalize key specifications as key performance indicators. The availability of early stage analytical models as well as basic geometry allows the designers to start incorporating estimates of aleatory uncertainty.

3. Detail design: The detail design entails a detailed focus on discrete components. In this phase the details including form, surfaces, tolerances, dimensions, and material are decided upon based on the design of the previous phase. This entails a significant focus on aleatory uncertainty as the design as well as manufacturing intents are finalized and key performance indicators are simulated via modelling. The interaction uncertainty is integrated, controlled and managed in this phase via developing more detailed models of the system and understanding the physical processes and their interaction with each other. In addition to the epistemic uncertainty due to the decisions of this phase or previous phases, the existence of aleatory uncertainty in the value of physical entities and environmental impacts are unavoidable [229].

4. Testing and refinement: This is a notable phase in the design process as one of the major objectives of the phase is to identify, control, and reduce uncertainty. The key activities in this phase are to develop and test functional prototypes to ascertain the product performance as per the requirements in presence of different uncertainties managed in the earlier phases. Additionally, this phase also allows to identify the uncertainties that may not have been addressed or considered. As such, the interaction and aleatory uncertainties are significantly addressed in this phase and any outstanding ambiguity or epistemic uncertainties are accounted for.

5. Production ramp-up: This phase is characterized by a high degree of focus on aleatory uncertainty as the key production plans are put into action and any unexpected process variations and uncertainties are managed and resolved before the production ramp up process is converted into full production.

Fig. 8 shows the relative influence of the different types of uncertainty through the phases of the design process. In addition to the classical component design process, it is important to also consider how uncertainty plays a role in higher-level project design. The design of complex systems is more heavily weighted toward the early stages, and the interaction uncertainty - driven by

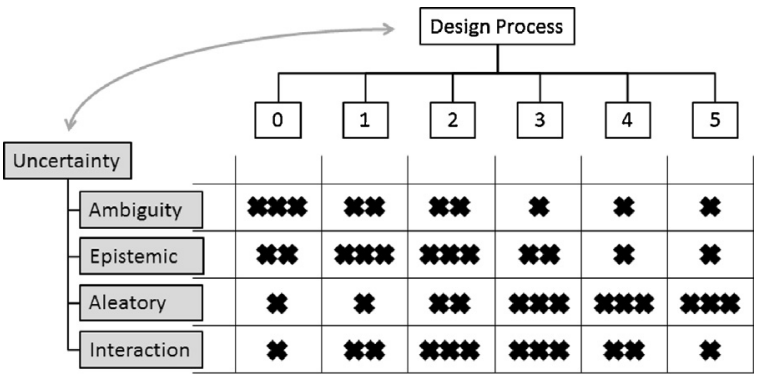

Fig. 8. Effect of uncertainty in different phases of product development process. complexity - plays a large role in the risk of the process. A discussion of the evolution of uncertainties in cost over a product lifecycle is described by Schwabe et al. [261].

\subsection{Uncertainty and risk}

To clarify the scope of uncertainty management in design, it is important to identify the consequences of these uncertainties: The uncertainties lead to risks. Concise Oxford Dictionary defines 'risk' means: "hazard, chance of bad consequences, loss, exposure to chance of injury or loss". In the context of system engineering, risk is classified into technical (feasibility, operability, manufacturability, and systems effectiveness), cost (estimates, goals), schedule (technology/material availability, technical achievements, milestones), and programmatic (resources, contractual) [150]. Browning [43] proposes an overview on the link between risks and uncertainties. The sources of risk in product development are divided into six categories, described below and summarized in Fig. 9:

1. Performance risk-Uncertainty in the ability of a design to meet desired quality criteria (along any one or more dimensions of merit, including price and timing) and the consequences thereof.

2. Schedule risk-Uncertainty in the ability of a project to develop an acceptable design (i.e., to sufficiently reduce performance risk) within a span of time and the consequences thereof.

3. Development cost risk-Uncertainty in the ability of a project to develop an acceptable design (i.e., to sufficiently reduce performance risk) within a given budget and the consequences thereof.

4. Technology risk-A subset of performance risk: uncertainty in capability of technology to provide performance benefits (within cost and/or schedule expectations) and the consequences thereof.

5. Market risk-Uncertainty in the anticipated utility or value to the market of the chosen "design to" specifications (including price and timing) and the consequences thereof.

6. Business risk-Uncertainty in political, economic, labor, societal, or other factors in the business environment and the consequences thereof.

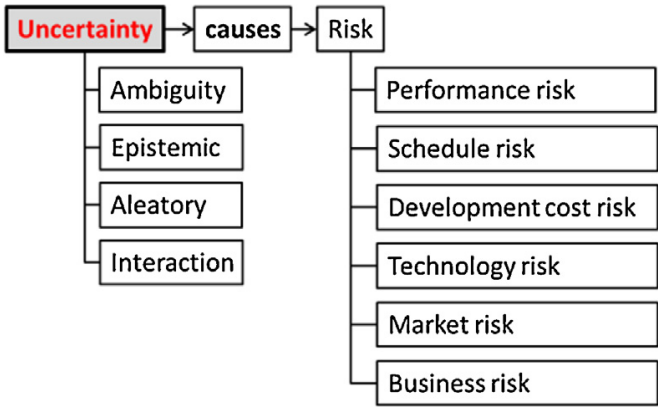

Fig. 9. Uncertainty and risk taxonomy.

All types of uncertainty cause risks in that they affect the design process [133]. Many techniques exist to reduce and mitigate these risks [56]. To clarify the scope of these techniques, McManus and Hasting [209] propose a framework: "Uncertainties lead to Risks or Opportunities, which are handled technically by Mitigations or Exploitations, which hopefully lead to desired Outcomes". Based on this framework, the taxonomy of uncertainty management is provided in Fig. 10. In the next section of this chapter, this taxonomy is used to define the aim, the scope and the position of various approaches: Robust design, Reliability based design, and tolerancing. 


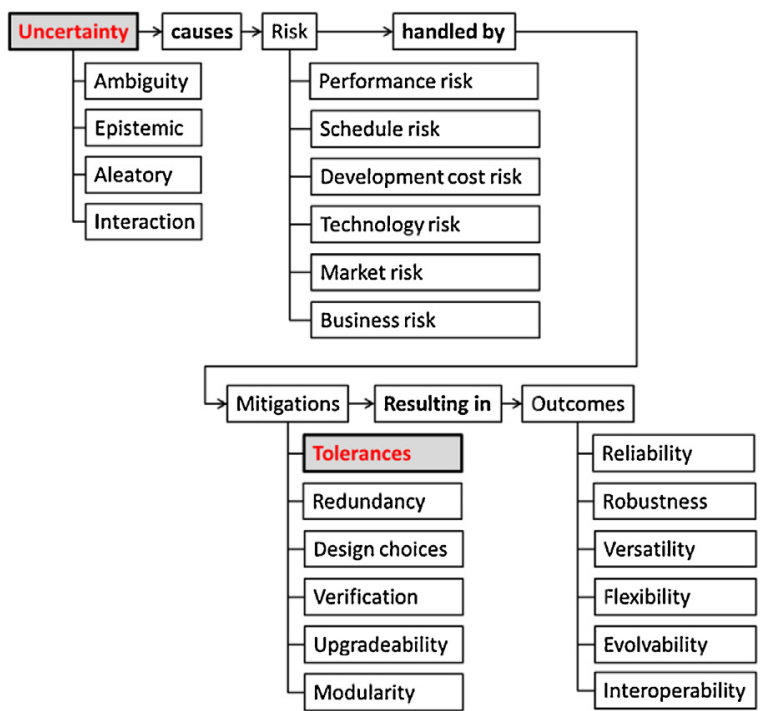

Fig. 10. Uncertainty management taxonomy.

\subsection{Robust design}

Robustness refers to performance stability in engineering. Robust design is a set of engineering methods widely successful in reducing sensitivity to such noise factors as design parameter variation, customer use conditions, manufacturing variability, and degradation of a system over time.

Robust Design Optimization (RDO) aims at minimizing the sensitivity of the performance under variability. RDO methods intend to achieve systems with slight performance variations around their nominal values. The primary objective of RDO is to reduce the uncertainty through selection of the values of design variables $X$ while considering the performances $Y$ so that the mean value of the performance $\mu_{Y(X)}$ and their standard deviations $\sigma_{Y(X)}$ are within acceptable range of the design outcomes.

Find : $\quad X$

Minimizing : $w \cdot \mu_{Y(X)}+(1-w) \cdot \sigma_{Y(X)}$

Choi [65] categorizes robust design into four types. Type-I robust design is related to identifying design variable values to satisfy the required performance requirements despite the variations in noise factors [2]. Type-I RDO manages Aleatory uncertainty from noise variables. Type-II RDO deals with uncertainty in the value of design variables while considering noise, thereby, addressing two sources of aleatory uncertainty. As shown in figure X by the yellow region, both Type I, and II RDO aim to stabilize the system response while considering aleatory uncertainty. Type-III RDO deals with managing the effects of uncertainty introduced by identifying adjustable ranges for design variables, that satisfy sets of performance requirement ranges and are insensitive to the variability within the model. This is shown by the orange region of decreased system response variability in Fig. 11. In addition to addressing Aleatory uncertainty, Type-III RDO also deals with the epistemic uncertainty related to the phenomenon and behavior of system. Type-IV is related to the model uncertainty including errors in decisions and accumulated errors by series of uncertain subsystem models [65].

The search for robust solutions has led to analyses and modelling of uncertainties due to manufacturing imperfections, external uncertainty and error modelling. These uncertainties can be aleatory or epistemic by nature [226]. In the past few years, many approaches have been developed to deal with uncertainty such as robust design methodology (RDM) [212]. Most of these approaches, however, focus on downstream design phases 3-5 and are in form of analytical or numerical models, intended mainly to study the impact of uncertainty on key design parameters [213]. This is due to presence of ambiguity and epistemic

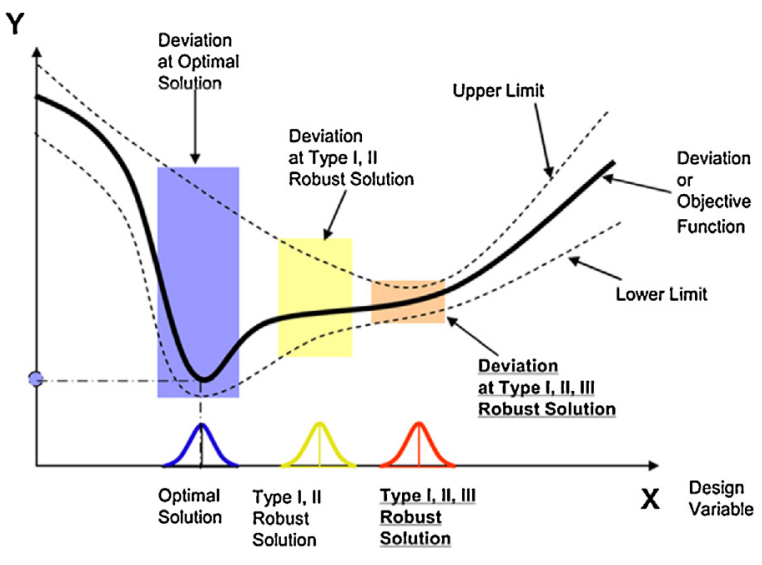

Fig. 11. Type-III robust design [65].

uncertainty in earlier phases, which hinders the application of concrete numerical models in earlier phases. A few models aim to resolve early stage uncertainty through integration of abstract modelling techniques such as function modelling with metamodels of systems with uncertainty integration [83,103,204]. Some approaches have addressed the integration of robust design in early phases with downstream phases while considering the impact of the design parameters on the sensitivity to variation as well as cost [101].

It was mentioned at the start of this chapter that design problems are 'ill-defined'. Robust design strategies help built robustness in the process which is one of the critical outcomes of the design process. Robustness of a design ensures that despite the types of uncertainties that have been considered in the design process the product's performance will not be affected. In current industrial practice, robustness is integrated in activities such as design verification, tolerances, and design choices. This in turn primarily reduces the performance risk, development cost risk, and has a subsequent effect on the market and business risk [44].

\subsection{Reliability based design}

Reliability can be defined as the likelihood that a component (or a system) will perform its intended function without failure for a specified period of time under stated operating conditions. Reliability is characterized by the probability that the system will perform for a certain time. Reliability Based Design Optimization (RBDO) methods are based on the probability distributions to describe variability of design variables and model parameters. They intend to achieve systems with an acceptable level of reliability (failure probabilities) and a satisfying level of performance (Fig. 12).

A solution is said to be reliable if the probability of satisfying each constraint is greater than a specified reliability level. RBDO methods consist of design optimization with a reliability assessment,

$$
\begin{array}{ll}
\text { Find : } & X \\
\text { Maximizing : } & \operatorname{Prob}\left(Z(X) \in\left[Z_{L L}, Z_{U L}\right]\right) \\
\text { subject to : } & H(X)>0 \\
& X \in[L L, U L]
\end{array}
$$

with,

$\begin{array}{ll}X & \text { Design variables } \\ Z & \text { Performances which depend on } X \\ H(X)>0 & \text { Design constraints } \\ \operatorname{Prob}\left(Z(X) \in\left[Z_{L L}, Z_{U L}\right]\right) & \text { Conformity probability } \\ L L, U L & \text { Lower and upper limits }\end{array}$

Reliability analysis is an essential activity employed to manage and reduce performance risk. It does so by mitigating epistemic and aleatory uncertainty to a probability that is acceptable given 


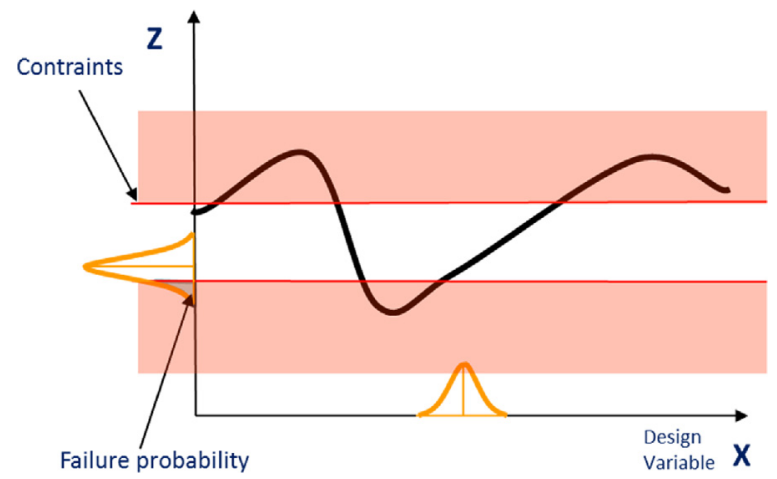

Fig. 12. Reliability illustration.

the technology, market, and business risks. RBDO techniques are extensively used in phase 3 of the design process, mostly in the form of statistical and stochastic models to estimate the product function in terms of its mean life. Several qualitative techniques are also used in the earlier design phases (phases 1 and 2) to mitigate the interaction uncertainty by uncoupling the design variables and their effect on reliable system performance.

\subsection{Tolerance design}

All manufacturing processes exhibit variation. This variation is described in terms of aleatory uncertainty in terms of process probability density function of a bounded process accuracy or precision with a mean and variability. Due to this uncertainty, it is impossible to attain theoretically nominal dimensions. Tolerancing is a set of activities involving various tools and methods which allow the designers to manage the manufacturing uncertainty during the product development process. Tolerancing differs from robust design and reliability based design by focusing and emphasizing on the aleatory uncertainty introduced due to manufacturing processes.

The aleatory uncertainty in the manufacturing process translates into two fundamental aleatory uncertainties in the final geometry of the product: uncertainty in size, i.e., attaining nominal dimension, and uncertainty in form, i.e., attaining a nominal shape. Increases in either or both of these uncertainties directly result in an increase in risk. This may be: performance risk in form of loss in product performance due departure from intended function, with an impact on robustness and reliability; schedule risk due to loss of interchangeability of different components of the part, resulting into lower flexibility, evolvability, and interoperability, and subsequently missed deadlines and adherence to schedules; or development cost risk, by unforeseen batch rejects and reworks. These risks increase the product's market and business risk, thereby risking the profitability of the company. Tolerancing allows the mitigation of these risks, contributing significantly to robustness, reliability, flexibility, evolvability, and interoperability of the final product.

Tolerance design comprises three iterative activities: tolerance specification, allocation, and analysis. These activities are driven by requirements of the product's performance, customer requirements, manufacturability, and interchangeability (Fig. 13). Currently they are extensively used in form of analytical, numerical, stochastic, and statistical methods applied in Phase 3: detail design to specify tolerance while considering the above constraints to minimize and manage uncertainty. There are limited applications of tolerancing in upstream design process. Dantan et al. [83,237] have provided an integrated method to consider robust design and tolerance design activities. Ebro and Howard [101] have related tolerance sensitivity analysis to a products core function as well as manufacturability and success in the early design phases. Zhang et al. [328] also propose a concurrent method to develop the structure of tolerance assignment in design.

The tolerancing activity is a highly coupled process that addresses and guides allowable manufacturing uncertainty in the process.

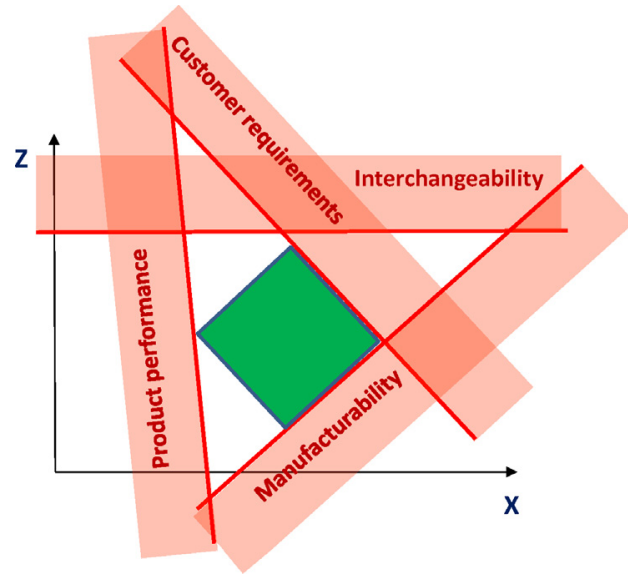

Fig. 13. Tolerance design considerations in design process.

However, this also directly affects the function of the product due to the acceptable change in the allowed variation. Tolerancing itself is linked to a number of design decisions such as cost, manufacturing process selection, and required design specification [110]. It is present significantly in the downstream product design process and has a critical effect on the product development and manufacturing, eventually effecting products' success.

\subsection{Observations}

It is important to point out the difference in the primary foci of different techniques discussed in this section. Firstly, all of the above techniques are primarily sets of tools and methods to identify, model, simulate, and optimize uncertainties in the product design and development processes; however, the primary focus of each method is different. Robust design techniques primarily manage and mitigate uncertainty related to the selection of values of design variables and aim to reduce the uncertainty in the product performance. The reliability based methods aim to reduce the uncertainty of the product failure in terms of its mean life. Tolerance design activities primarily focus on managing and reducing the risk in product design by managing manufacturing uncertainty while assuring the product performance and customer requirements. It must be noted that all of these activities are mutually coupled and are iteratively and concurrently carried out to minimize uncertainty in the design process. These techniques are an intermediate activity in the design process that translates the customer requirements into a successful design with the required outcomes as shown in (Fig. 10 at end of Section 3.1).

\section{Specification and verification of allowable uncertainty}

A clear picture of the importance of standardizing the specification, verification and exchange of product geometry is given by Srinivasan [282]. The picture is completed by the discussion of the evolution of these standards driven by the need of reducing their uncertainties and ambiguities.

In the following, the current situation in terms of tolerance specification and verification will be summarized.

\subsection{Tolerance specification}

The International Organization of Standards (ISO) has produced many standards related to dimensioning and tolerancing [153,154,158-165,167-169,174]. Each of these standards cover one or more cells in the Geometrical Product Specification (GPS) matrix [172]. The GPS matrix defines nine geometrical property categories (six related to the geometry, i.e. size, distance, form, orientation, location, run-out, and three related to the surface finish, that is profile surface texture, areal surface texture, and surface imperfections). For each property, a 'chain of standards' is 
defined, grouping all the standards related to such property and defining symbols (syntax), meaning (semantics, i.e. mathematical foundation), and measurement procedures for it. The chain is formed by 'chain links', which group the standards related to some specific step in the property definition. The recently redesigned [223] GPS matrix reserves the first three chain links to the tolerance specification issue $(A-C)$, the last three chain links to the tolerance verification issue $(E-G)$, while chain link D consists of ISO GPS standards defining the requirements for comparison between specification requirements and verification results.

The American Society of Mechanical Engineers (ASME) has collected the majority of GD\&T requirements in ASME Y14.5 standards [24]. Although ASME GD\&T [24] does not explicitly cover the mathematical definition and the verification issue and the link between tolerance specification and verification, other ASME standards deal with these instrument-specific topics [19-22].

ISO GPS 'chain of standards' clearly testifies one important issue: the need to harmonize verification with specification of product tolerances, thus reducing uncertainties in the information flow from design to manufacturing. Are we sure that the design intent is clearly transferred to manufacturing?

It is worth noting that this issue has been a fundamental reason for developing manufacturing oriented standards [2426,173]. These standards refer to well-established manufacturing fields: casting, forging, and the production of molded parts and composites. Nevertheless, problems may arise if new manufacturing technologies enable the production of new products, such as those that are micro- or nano-scaled, or additively-manufactured. Considering the latter (AM) case, it is possible to address these problems distinguishing between process-driven issues and issues highlighted by the capabilities of additive manufacturing, despite the alleged benefit of "complexity for free" [4,321].

\subsection{ASME-ISO main differences in tolerance specification}

The best-known difference between the ASME and ISO tolerance specification standards is in the governing principle that size controls form (called Rule \#1) in ASME, where size is independent of form in ISO. However, ASME allows to use the independency symbol to override Rule \#1, and ISO uses the enveloped principle to invoke Rule \#1 if required.

Despite this fundamental difference, ASME and ISO standards have more similarities than differences, and a convergent path seems in progress. Heysiattalab and Morse have recently reviewed the main differences [141] that the two standards have with respect to terminology (Table 1 ) and symbols (Table 2). The most relevant are the different interpretations that ASME and ISO have for some identical tolerance symbols, actual values, and material conditions. Table 3 shows those differences.

\subsection{D Tolerance specification}

GD\&T requirements need to be transferred to manufacturing and inspection. However, until recently, GD\&T information consists in two dimensional annotations on drawings. Since 3D

Table 1

ASME and ISO proprietary symbols.

\begin{tabular}{|c|c|c|}
\hline Standards & Descriptions & Symbol \\
\hline \multirow[t]{2}{*}{ ASME } & Modifying symbols & (O) (T) (U) $D S \mathrm{ST}$ \\
\hline & Dimensioning symbols & I I $\downarrow V \mid S F$ \\
\hline \multirow[t]{2}{*}{ ISO } & Additional symbols & 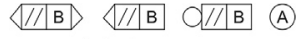 \\
\hline & & $\begin{array}{c}\mathrm{UZ}-\mathbb{I I} \text { ACS NC LE CZ } \\
\longrightarrow \text { (R E }\end{array}$ \\
\hline
\end{tabular}

Table 2

Comparison of ANSI Y14.5 and ISO terminology.

\begin{tabular}{ll}
\hline ASME & ISO \\
\hline Basic dimension & Theoretical exact dimension (TED) \\
Inner boundary & - \\
Outer boundary & - \\
Feature control frame & Tolerance frame \\
True position (TP) & Theoretical Exact Position (TEP) \\
Circularity & Roundness \\
Reference dimension & Auxiliary dimension \\
\hline
\end{tabular}

Table 3

Different interpretations of standards.

\begin{tabular}{|c|c|c|}
\hline Tolerance & ASME & ISO \\
\hline Flatness & Applied only to one surface & $\begin{array}{l}\text { Applied to one or two } \\
\text { surfaces }\end{array}$ \\
\hline $\begin{array}{l}\text { Orientation } \\
\text { applied to axis } \\
\text { or median } \\
\text { plane }\end{array}$ & $\begin{array}{l}\text { Applied to a perfect-form } \\
\text { feature axis or plane } \\
\text { (mating envelope) }\end{array}$ & $\begin{array}{l}\text { Applied to the extracted } \\
\text { axis, line or median surface }\end{array}$ \\
\hline $\mathrm{MMC}^{*}$ or $\mathrm{LMC}^{* *}$ & $\begin{array}{l}\text { Not applied to concentricity } \\
\text { and symmetry }\end{array}$ & $\begin{array}{l}\text { Applied to concentricity } \\
\text { and symmetry }\end{array}$ \\
\hline $\begin{array}{l}\text { Symmetry and } \\
\text { concentricity }\end{array}$ & $\begin{array}{l}\text { Applied to the median } \\
\text { points }\end{array}$ & $\begin{array}{l}\text { Applied to the extracted } \\
\text { median line or extracted } \\
\text { median surface }\end{array}$ \\
\hline Position & Applied only to a FOS ${ }^{* * *}$ & $\begin{array}{l}\text { Applied to a FOS or to a } \\
\text { plane }\end{array}$ \\
\hline Run-out & $\begin{array}{l}\text { Tolerance zone always } \\
\text { normal to the nominal } \\
\text { profile }\end{array}$ & $\begin{array}{l}\text { Tolerance zone normal or } \\
\text { non-normal to the nominal } \\
\text { surface of the part }\end{array}$ \\
\hline Profile & $\begin{array}{l}\text { Tolerance zone defined by } \\
\text { two equally or unequally } \\
\text { disposed surfaces or lines } \\
\text { about the true profile that } \\
\text { extend to intersection } \\
\text { points }\end{array}$ & $\begin{array}{l}\text { Tolerance zone defined by } \\
\text { two equally or unequally } \\
\text { disposed surfaces or lines } \\
\text { formed by sweeping a } \\
\text { sphere or a circle around } \\
\text { the nominal profile }\end{array}$ \\
\hline $\begin{array}{l}\text { Composite } \\
\text { tolerancing }\end{array}$ & $\begin{array}{l}\text { Used for positional and } \\
\text { profile tolerances }\end{array}$ & $\begin{array}{l}\text { Means two independent } \\
\text { tolerances }\end{array}$ \\
\hline
\end{tabular}

models have almost completely replaced 2D drawings as the master for product technical data in manufacturing industry $[282,299]$, the need arose for standardized indications of dimensions and tolerances on 3D models [119] or, better, inside modelbased engineering (MBE) packages.

This need has led to the development - for over 30 years - of a family of standards, the ISO 10303 series, known as STEP (STandard for the Exchange of Product model data) that describes standardized data models in several Application Protocols (AP). In particular, AP242 entitled 'Managed Model Based 3D Engineering' is the most comprehensive product model-based definition (MBD) of STEP, as it contains several types of 3D model data, including dimensional and geometric tolerances [171]. It is developed using a modular architecture [118]. Its modules use the EXPRESS schema language, as appropriate for the intended applications, to define the data models [231].

The transition to digital manufacturing is rising the importance of incorporating Product and Manufacturing Information (PMI) in the (MBE) packages [322]. It also enables Computer Aided Manufacturing (CAM) software to define and validate machinereadable instructions for manufacturing and Computer Aided Engineering (CAE) software to validate and optimize the product definition. Manufacturers are recognizing the benefits of MBD and moving away from reliance on 2D drawings to represent PMI [194].

As a standard language for PMI does not exist yet, CAD/CAM software vendors develop and implement their own PMI in their software. The software vendors' implementations are tested in an 'Implementer Forum' $[61,62,63]$ to ensure that PMI has been correctly implemented and can be exchanged smoothly, even if partially, using the STEP standards. The CAx Implementer Forum (CAx-IF) defines recommended practices for interoperable data exchange using STEP files [194].

An example of PMI related to GD\&T is the ANSI "Quality Information Framework" (QIF) [11]. It adopts the modern 
Extensible Markup Language Schema Definition (XSD) as information modeling language, and it covers (quality) metrology systems [141]. It is a feature- and characteristic-based data format that defines four aspects of a characteristic: Definition, Nominal, Item and Actual. This allows QIF to both define PMI requirements and report measurements results in a common data model, allowing the linking of results to the original design.

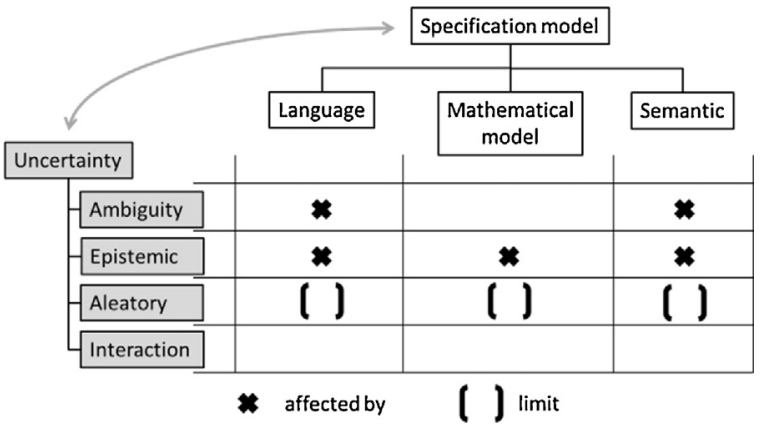

Fig. 14. Mapping between the main concepts of specification model and the uncertainties.

Another language to express the specification from function to verification is GeoSpelling [32]. The objective of the GeoSpelling language is to enable the semantics of specifications to be expressed and to define their meaning clearly. The concepts of GeoSpelling have been integrated into the ISO 17450-1 and -2 standards [167,169].

The continuous review and revision of the different standards and the growing industrial interest in digital manufacturing, it is expected to reduce the information loss in data translation among different MBE packages and, with the help of PMI, to mitigate the uncertainties in the information content. However, both the ASME and ISO systems continue to struggle with the increased complexity of products and their requirements.

\subsection{Tolerance verification}

Although ASME GD\&T [25] does not cover this aspect, the need for tolerance verification is clearly stated in the ISO GPS $[148,167]$. The recently redesigned [223] GPS matrix reserves the last three chain links to the problem of tolerance verification:

- Chain link E, 'measurement', refers to the optimal procedures and requirement for the performance of measurements to verify conformance to tolerances;

- Chain link F, 'measurement equipment', defines the requirements of the equipment used to verify tolerances;

- Chain link G, 'calibration', states how the measurement equipment must be managed to guarantee the accuracy of tolerance verification.

- Furthermore, chain link D 'conformance and non-conformance' acts as a liaison between the links relative to the definition of tolerances and the links related to the verification of the same.

The use of low accuracy verification systems can lead to an apparent reduction of the process capability [186], which is of course of great impact on the tolerancing process.

Uncertainty has been deeply studied in the field of metrology, and quite often the term "uncertainty" directly refers to the GPS measurement uncertainty [318], which is aleatory uncertainty. When trying to prove the conformance to geometric tolerance, the uncertainty reduces the reliability of any statement. This issue is treated in GPS chain link D, and the reference standard is the ISO 14253-1 [170], which states rules for proving the conformance of parts to a tolerance. The main rule is that the uncertainty always 'plays against' who is performing the test. This means that the conformance zone is reduced in when a supplier performs the test trying to prove conformity, and is enlarged when a customer aims at proving nonconformity.

Chain link G is in general covered by the ISO 14253-2 standard [166]. Anyway, the rules stated in this standard are very generic. More specific procedures for the evaluation of the measurement uncertainty are covered in the ISO 15530 series [155]. However, these standards do not cover the GPS method uncertainty (ambiguity) arising from the risk of misunderstanding the tolerances, in particular, when high precision part or complex surfaces are involved. The definition of a common language for tolerancing and tolerance verification is yet to be realized. A significant step in this direction, in the case of features of size, has been achieved with the introduction of the ISO 14405-1 standard [174]. The new syntax in this standard allows for the definition of the type of size (two points, least-squares, etc.) together with the size value. An effort in this direction (the reduction of the ambiguity when moving from specification to verification) has also been undertaken with the definition of the skin model $[13,258,257]$ and of the GeoSpelling language [32,201,202] proposes to solve this problem through a revision of the STEP standard. Examples of integrated definition of the tolerance and verification have been proposed in the field of gears $[46,75,78,80,298]$.

\subsection{Observations}

Fig. 14 summarizes this chapter. The main objective of specification model is to provide a language to limit the manufacturing imperfections (aleatory uncertainty). These languages or models are affected by ambiguity. To reduce this ambiguity, new standards and models have been developed, but their complexity increases the epistemic uncertainty (lack of knowledge). In general, designers are not familiar with all of the new concepts that appear in the standards. One of the challenges is to find a compromise between the ambiguity and the epistemic uncertainty due to the specification models and languages.

\section{Tolerance analysis-uncertainties}

In this chapter, tolerance analysis and variation simulation is described from three main perspectives: (1) tolerance models for representing the geometrical deviations on individual parts (Section 5.1), (2) System behavior models, for representing how variation propagates in a product or an assembly (Section 5.2). (3) tolerance and variation analysis techniques (Section 5.3). Section 5.4 discuss and summarizes the different uncertainties involved in tolerance analysis using the classification given in Chapter 2 .

\subsection{Tolerance models}

Tolerance models are the first step towards translation of the functional requirements and geometric relations in form of quantifiable mathematical expression. A significant amount of research efforts has been carried out in the last decade to explore the mathematical models for geometric deviation representation: variational geometry approach, skin model shape, modal representation, and others. Among the most commonly used are variational geometry approaches. In these approaches, the form defects are neglected. These approaches are based on the parameterization of deviations from theoretic geometry. The real geometry of parts is considered by a variation of nominal dimension or it is bounded by a variation (position and orientation) of the nominal geometry [135]. The orientation and position deviations of each surface could be represented by TTRS [6,36,39,66,67,91], kinematic formulation $[101,122,197,245,250]$, small displacement torsor (SDT) $[42,92,127,128,288]$, matrix representation $[120,142]$, or vectorial tolerancing $[123,139,319]$. In the TTRS model, any part can be represented as a succession of binary surfaces associations forming a tree. Additionally, each surface association, termed as a TTRS object, is represented by a set of minimum geometric datum elements (MGDE). Once established, each TTRS can be given appropriate 
geometric dimensioning and tolerancing (GD\&T) symbols through a general procedure making use of GD\&T tables and combination rules. Thirteen different constraints for dimensioning and tolerancing were proposed by Clemént et al. [67].

The geometric or dimensioning tolerances are represented by deviation domain $[120,127,129,180]$, Tolerance-Map ${ }^{\mathbb{R}}[85,86,220]$ or specification hull $[76,79,81,246,247,336]$. These three concepts are a hypothetical Euclidean volume in parameter space which represents possible deviations in the size, orientation and position of features. The T-Map point-space corresponds to possible locations and variations of a feature which can arise from tolerances on size, form, and orientation on a part. The model has been applied to the ASME and ISO Standards for geometric tolerances $[3,38,85,86,220,268]$.

The TTRS model, the Deviation Domain model and the T-map model were analyzed and compared by Ameta et al. [6]. The methods are quite similar in their aim, using different mathematical approaches. No model is fully complete when it comes to representing the tolerancing standard but provide a good support for tolerance analysis. Specifically, modelling of form errors is not possible.

Often, in early concept phases, before any physical parts are manufactured, the exact variation behavior of the parts is not known. However, typical manufacturing behavior or expected form errors needs to be included in the tolerance analysis. Methods to model part variation by superposing different variation modes had been proposed by Chase et al. [15,40,49,57,58,84,143,147,109, $205,242,258]$. Manufacturing signature for tolerance analysis was addressed in Ref. [234]. The skin model, proposed by Ballu and Mathieu [30], is a comprehensive framework that includes position, orientation and form defects. The modal representation method of geometrical deviation decomposition has extensively been studied. Huang and Ceglarek [147] proposed discrete-cosinetransformation (DCT) based on decomposition method for form defects modeling. Samper et al. [251] developed the Discrete Modal Decomposition (DMD) considering modal shapes of a discretized feature. Usually, the technical interpretation of these modal representations is not easily achieved.

To capture and model part variation, Design of Experiments (DOE) in combination with manufacturing simulation (stamping, molding, forging) and principal component analysis (PCA) has been proposed in Ref. [198,192]. Methods based on morphing technologies and inspection data from similar projects have been proposed in Ref. [300]. The description of part variation is used together with Monte Carlo simulation in the assembly variation simulation. All of these methods use a simplified triangular format (VRML, STL, or FEA meshes) to represent part geometries, similar to the skin model approach. All of these models are affected by model uncertainty as it is not possible to model and identify all manufacturing imprecisions.

\subsection{System behavior models}

Fig. 15 shows a typical tolerance analysis situation where tolerances on individual parts accumulate into tolerance on the assembly. Or conversely, as described in chapter 6 , the allowable limits on the assembly must be assured by the limits on the parts.

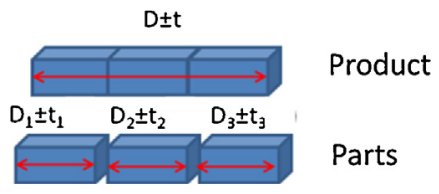

Fig. 15. Tolerance analysis.

Analyzing the effect of variation in a product, model, or an assembly requires establishing relations between the allocated tolerances and the critical product dimensions in form of Models.
These models for tolerance analysis can roughly be divided into analytical models and numerical simulation models.

\subsubsection{Analytical models}

In terms of degrees of freedom, mechanisms can be divided into two main categories: iso-constrained mechanisms, and overconstrained mechanisms. Given their impact on the mathematical formulation for the problem of tolerance analysis, a brief discussion of these two types is given by Ballu et al. [33]:

\section{- "Isoconstrained mechanisms are quite easy to grasp. Geometrical deviations within such products do not lead to assembly problems; the deviations are independent and the degrees of freedom catch the deviations. When considering small deviations, functional devia- tions may be expressed by linear functions of the deviations." \\ - "Considering overconstrained mechanisms is much more complex. Assembly problems occur and the expression of the functional clearance is no more linear. Depending on the value of the manufacturing deviations: the assembly is feasible or not; the worst configuration of contacts is not unique for a given functional deviation. For each overconstrained loop, events on the deviations have to be determined: events ensuring assembly, events corresponding to the different worst configurations of contacts. As there are different configurations, the expression of the functional deviation cannot be linear."}

Therefore, isoconstrained tolerances can be modeled in form of explicit analytic functions of general form $Y=f(X)$, where $f$ is the response (characteristic such as gap or functional characteristics) of the assembly.

A commonly used method for 3D variation simulation and tolerance analysis in industry is the so called "point-based method". The method is used in many of the commercial computer-aided tolerancing (CAT) tools. In this method, mating conditions between parts are described by defining point-based master locating schemes. The locating schemes define coordinate systems that are aligned during assembly. For a master location scheme, corresponding to an ABC datum frame, typically a pointbased orthogonal 3-2-1 locating scheme is used (see Fig. 16 left). A number of different locating schemes exist and are used in various industrial situations, see Söderberg, Lindkvist et al. [277]. Subordinate (local) locating schemes can be defined to describe dependencies on a single part. Tolerances are applied as variation in the locating points, corresponding to the allowed tolerance, defined by the tolerance for the specific feature. Typically, holes, slots, planes and surfaces are used as locating features and tolerances are typically position, flatness, surface profile etc. For non-rigid parts, over-constrained locating schemes with additional support points, are used (see Fig. 16 right). The concept utilizes transformation matrices to calculate how variation propagates in the assembly. Critical dimensions in the assembly (object for the analysis) such as position, clearance, parallelism, angles, etc. are also evaluated from these point locations.
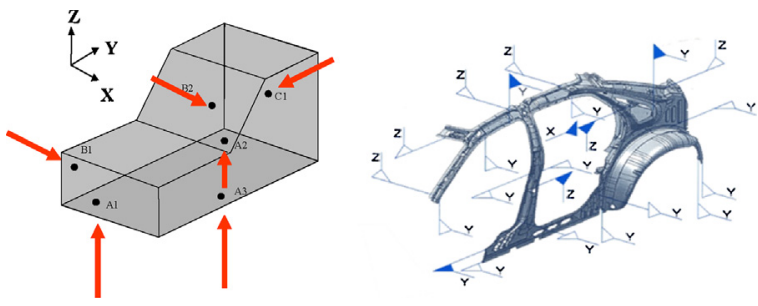

Fig. 16. Rigid and non-rigid locating schemes.

The point-based method is a straight forward method that captures rotations, translations and non-linearity and is often combined with Monte Carlo Simulation. The method is not limited to normal distribution tolerances but use any distribution or samples of data, 
such as inspection data, as input. Robustness optimization by optimizing of locator positions has been presented in Wang and Pelinescu [305]. During modelling, GD\&T specifications are broken down to variation in individual points on part features. When using triangular formats such as STL or VRML (or FEA meshes for non-rigid analysis) all points/nodes of the part features can be assigned a tolerance. However, usually only points on features contributing to variation propagation, or features to be studied in the analysis, are assigned a tolerance. Tolerances assigned to points on the same feature are often defined with a dependency. CAT tools such as RD\&T, VSA, and 3DCS use this approach to support the product development process and bridge the gap between tolerancing and product development $[97,102,185,271,275,276]$. Fig. 17 shows an example from variation simulation in RD\&T where the color coding of the rear lamp indicates the robust (blue) and sensitive (red) areas due to variation in locators (mating points). The statistical distribution in the figure insert shows the expected variation in a critical product dimension - in this case flush between the rear window and the rear lamp.

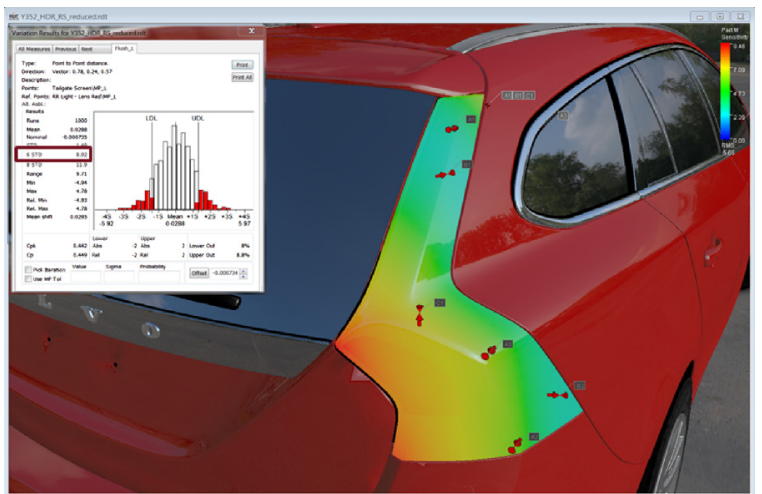

Fig. 17. Variation simulation in RD\&T [276]

In the general case of analytic formulation, the mathematical formulation of tolerance analysis takes into account the influence of geometrical deviations on the geometrical behavior of the mechanism and on the geometrical product requirements; all these physical phenomena are modeled by constraints on the parameters [74]:

- Composition relations of displacements in the various topological loops express the geometrical behavior of the mechanism. They define compatibility equations between the deviations and the gaps. The set of compatibility equations, obtained by the application of composition relation to the various loops, results into a system of linear equations. Successful solution of this system of equations indicates solution.

- Interface constraints model the assembly constraints. These constraints characterize non-interference or association between substitute surfaces, which are nominally in contact. These constraints also limit the gaps between substitute surfaces. In the case of clearance contact, the relative positions of substitute surfaces are constrained technologically by the non-interference. The interface constraints result in a system of linear inequalities. In the case of slipping and fixed contact, the relative positions of substitute surfaces are constrained technologically in a given configuration by mechanical action.

- The functional requirements model the core functional constraints by limiting the orientation and the location between surfaces, which are in functional relation. This requirement is a condition on the relative displacements between these surfaces. This condition is also modelled by a system of linear inequalities.

\subsubsection{Numerical simulation models}

In some cases, the geometrical deviations impact some nongeometrical functional requirements. To simulate the influences of geometrical deviations on these requirements, an analytic formulation cannot possibly be employed [45]. Instead, it is necessary to use numerical simulation for which it is possible to compute a value for $\mathrm{Y}$ given values of deviations and gaps: $\mathrm{Y}=\mathrm{f}_{\text {numerica simulation }}(\mathrm{X})$ or $\mathrm{Y}=\mathrm{f}_{\text {numerica simulation }}(\mathrm{X}, \mathrm{G})$.

For modelling variation propagation in assemblies with nonrigid parts, finite element analysis (FEA) may be used. An assembly stiffness matrix, based on the stiffness matrixes for the individual parts, describes the response in the output parameters. FEA is often combined with the point-based method and Monte Carlo Simulation. The method allows over-constrained locating schemes that result in bending during assembly due to variation in parts and fixtures. Fig. 16 (right) shows a 17-7-1 non-rigid locating scheme for a body side of a car.

To reduce computational time, the method of influence coefficient (MIC) is used in most MC based variation simulation approaches [195]. The main idea of MIC is to find a linear relationship between part deviations and assembly deviations after spring-back. A sensitivity matrix, calculated using FEA, describes that linear relationship. The sensitivity matrix is then used to calculate the response in each MC iteration.

In non-rigid analysis, mating conditions between parts are defined by constraints between parts and/or parts and fixtures. This is normally done by constraining nodes in the FEA model. Due to part variation and bending during assembly, new contacts may occur during this process. These contacts act as new constraints and must therefore be taken into consideration. Contact modeling for non-rigid analysis was addressed by Dahlström and Lindkvist [70], Wärmefjord et al. [308], and Lindau et al. [193].

Variation simulation for non-rigid sheet metal parts and assemblies is described in Refs. [193,206,306,307,309]. A tolerance analysis methodology for sheet metal assembly based on physical/ functional modelling of the fabrication error using the beam-based model was described in Ref. [55]. The modelling method includes principles of decoupling automotive parts into beam members, modelling of beam-to-beam joint geometry, and identification of part locating points. Modelling variation propagation of multistation assembly systems with compliant parts was described in Ref. [48]. The problem of model growth in variation simulation is discussed and treated in Ref. [191].

In many types of assemblies, the joining process is a contributor to variation and a link in the chain from part variation to assembly variation. The joining process then needs to be modelled and included in the assembly model. For non-rigid parts, the joining sequence is crucial for how variation in the individual parts, fixtures and welding equipment will affect the final assembly. Fig. 18 shows an example where the same two parts, with the same fixture, are joined together using two different sequences. As can be seen, one sequence results in quite large deviation (red area) while the other does not. In a sense, the latter can therefore be seen as the more robust one. Joining sequence optimization is a nonlinear problem, and requires contact modelling [308]. Therefore, genetic algorithms are often used to find the optimal sequence $[310,263]$. Furthermore, in Ref. [52] the cycle time is simultaneously optimized and in Ref. [53] the assembly feasibility of nonnominal parts is considered. An important aspect is also the position variation of the welding gun [274].

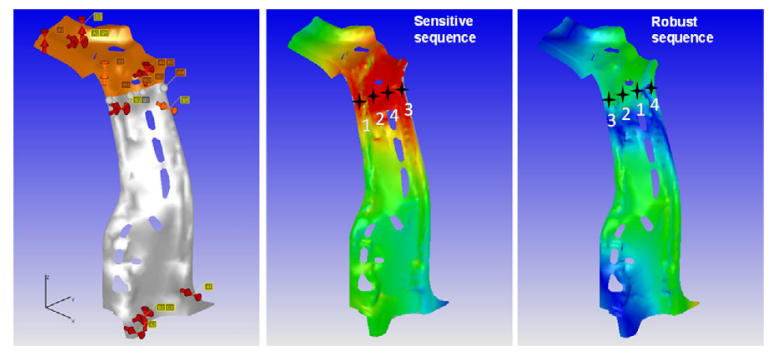

Fig. 18. The effect of joining sequence [310]. 
For many non-rigid assemblies the force needed to close the gap between the parts is quite critical. For sheet metal assemblies, this may affect the size of welding gun that may be used and for assemblies with plastic parts it affects the size and type of clips that may be used to join the parts [309]. For joining of dissimilar material, the effect of temperature is also quite important to consider [199].

To be able to perform non-rigid assembly variation analysis that correlates with reality, variation in material parameters may need to be considered. This is especially important for new material such as composites and for assemblies with mixed materials where temperature and joining may affect how parts interact geometrically with each other. Variation simulation for composites is treated in Ref. [175]. Geometrically induced variation simulation of stress in composites is treated in Ref. [273].

\subsection{Tolerance analysis techniques}

Usually, tolerance analysis can be either worst-case or statistical [224]:

- Worst-case analysis (also called deterministic or high-low tolerance analysis) is based on allocating dimensions and tolerances so that the probability of non-assembly is zero. The method considers the worst possible combinations of individual tolerances and examines the functional characteristic. Consequently, worst-case tolerancing can lead to excessively tight part tolerances and hence high production costs [114]. The main Worst-case analysis technique is the tolerance accumulation that simulates the composition of tolerances i.e. linear tolerance accumulation, and 3D tolerance accumulation. Based on the displacement models, several vector space models map all possible manufacturing variations (geometrical displacements between manufacturing surfaces or between manufacturing surface and nominal surface) into a region of hypothetical parametric space. The geometrical tolerances or the dimensioning tolerances are represented by deviation domain, T-Map ${ }^{\circledR}$ or specification hull. These concepts are discussed in Section 5.1. For tolerance analysis, above mathematical representations of tolerances allow calculation of accumulation of the tolerances by Minkowski sum of deviation and clearance domains [176]; to calculate the intersection of domains for parallel kinematic chain; and to verify the inclusion of a domain inside other one. The methods based on this mathematical representation of tolerances are very efficient for the tolerance analysis of linear models.

- Statistical tolerancing is a more practical and economical way of looking at tolerances and works on setting the tolerances so as to assure a desired yield. Statistical tolerances are based on probability density functions representing manufacturing processes. By using these functions and statistical process capability indicators [1], tolerance allocation is carried out that admits the small probability of assemblies which do not assemble or fail to function as required. Statistical tolerancing therefore results in a relaxation of tolerance intervals for individual dimensions, and in turn reduces the manufacturing costs associated with tighter tolerances. Statistical tolerance analysis computes the probability that the product can be assembled and will function under given individual tolerances. The majority of research examples are based on Monte Carlo simulation, and they allow the probability computations for both isoconstrained mechanisms $[59,178,182,224,269,270,296]$ and overconstrained mechanisms with numerical models [72,125,210,237,239,256].

\subsection{Uncertainties in tolerance analysis}

The final geometric quality of a complex assembly depends upon a number of phenomena. Tolerance analysis and variation simulation consequently involves a large number of uncertainties that can be categorized according to (1) tolerance models for representing the geometrical deviations on individual parts, (2) system behavior models for representing how variation propagates in a product or an assembly and (3) tolerance and variation analysis techniques (Fig. 19). It is essential to be aware of both modelling assumptions and simplifications, as well as model resolution. Regarding modelling of variation related to individual parts, the part variation itself, variation in material properties and gravity may need to be considered. For the system model, the assembly and joining process need to be modelled. This includes number, position and geometries of locators and supports as well as their variation and sequence. It also includes variation related to the joining process such as forces, sequences, effect of heat, etc.

This mapping between the main concepts of the tolerance analysis and the uncertainties shows the most divergence between tolerance analysis and Quantification of Margins and Uncertainty (QMU): tolerance analysis focuses on the manufacturing imperfections (aleatory uncertainty) propagation and QMU focuses on the model error (epistemic uncertainty) propagation [72,89]; neither of these uncertainties should be neglected. This observation shows the need for, and importance of, a global approach to manage uncertainties.

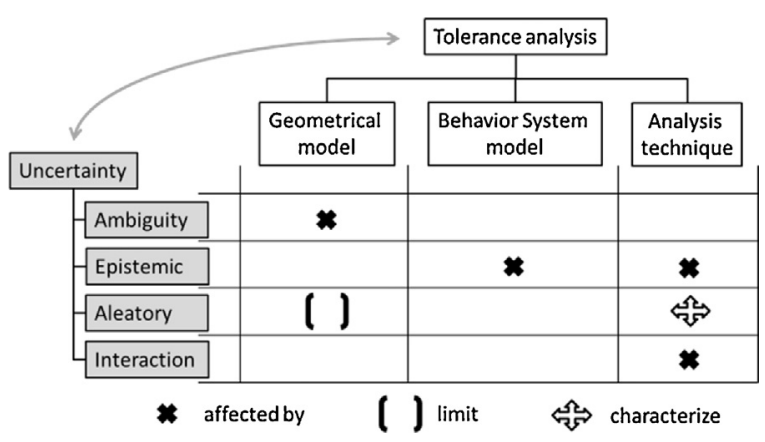

Fig. 19. Uncertainties in tolerance analysis.

\section{Tolerance synthesis and allocation}

Tolerance synthesis covers both quantitative and qualitative aspects in tolerancing and is a key issue for the optimization of tolerances. Closely related to design and manufacturing activities, tolerance synthesis enhances the scope of tolerancing to the product life cycle.

Etienne et al. [111] proposed decomposing tolerance design into three sub-activities: Geometrical requirement definition(Activity A1), Tolerance specification - qualitative determination of parts tolerances (Activity A2) and Tolerance allocation - quantitative allocation of part tolerances (Activity A3). These activities are shown in Fig. 20.

In this chapter tolerance synthesis is discussed from different perspectives. Tolerance specification or qualitative tolerance synthesis is presented with the purpose of linking functional

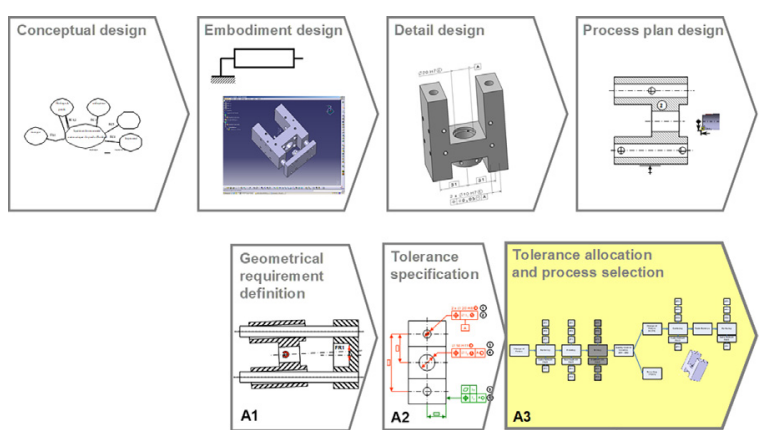

Fig. 20. Design and tolerancing processes [112]. 
and assembly requirements with tolerancing (tolerancing for function or tolerancing for design) as well as manufacturing requirements (tolerancing for manufacturing or tolerance transfer). Tolerance allocation is the assignment of tolerance values according to specific rules, strategies or process capability of manufacturing resources to enable tolerance analysis and tolerance optimization based on tolerance-cost models.

\subsection{Detail tolerance specification}

Tolerance specification or qualitative tolerance synthesis addresses the qualitative issues of tolerancing and the mapping of functional and manufacturing requirements into geometrical specifications in conformance with actual tolerancing standards. The aim of tolerance specification is to identify toleranced features and datums and to define the tolerance types, material conditions and tolerance symbols. Tolerance specification has been less investigated than other tolerancing research topics since it is mainly based on empirical rules or examples developed through guidelines, standards and industrial practices leading to nonuniqueness of solutions, making automation difficult to achieve, and often requiring trial and error strategies [264].

The most common approach for tolerance specification is based on Datum Reference Frame (DRF) selection which highlights contact surfaces in assembly or set-up surfaces in machining. Moreover, functional and manufacturing requirements, tolerance loops or stacks and Key Characteristics flowdown [292,317] can be related to DRFs.

Several tolerance specification methods have been proposed in the literature [16,267,329]. Among them TTRS (Technological and Topological Related Surfaces) [67] showed that from the perspective of the degree of invariance under the action of rigid motions, tolerance specification can be established on the basis of translational and rotational invariances and only a finite number of tolerancing cases can be generated using composition rules [190]. Functional decomposition and multi-level approaches have been developed to provide a systematic approach for mapping functional requirements into geometrical characteristics [31]. These approaches cover different design stages starting from conceptual design [82,249,77] and from the axiomatic design perspective [277], in are also used in the context of concurrent engineering [90], and considering the influence of contacts and assembly sequence $[10,252]$.

Formal approaches for tolerance synthesis have been developed by Dantan et al. [81] using a mathematical formulation based on quantifiers to enable an unambiguous expression of the conditions corresponding to assembly and function. Other approaches considering geometric reasoning and ontologies have been developed recently. Zhang et al. [330] use Polychromatic Sets Theory (PST) to generate assembly tolerance specifications and tolerance zone types. Zhong et al. [332] proposed an ontologybased approach for automatically generating assembly tolerance types. This work was extended through a meta-model with a description-logic based approach [331].

While design tolerances are not often translated directly (i.e. on a one-to-one basis) to tolerances addressed by manufacturing processes, tolerance transfer still must be realized to guarantee that manufacturing tolerances can fulfil allowable design tolerances under adequate manufacturing process parameters selection while respecting the capabilities of the machines [284].

Early transfer methods were based on 1D tolerance transfer and tolerance charts such as the method developed by Anselmetti and Bourdet [8] to translate functional and machining requirements into a set of machining dimensions through a linear model. This work was extended to 3D by Ballot and Bourdet using the small displacement torsor (SDT) theory [29]. Anselmetti et al. [9] developed a tolerance transfer method based on vectorial representation of the mobilities of the toleranced features and datum reference frame. A tolerance zone transfer method, based on the vectorial representation of tolerance zones and new mobility operators [54] was developed to enable tolerance specification in manufacturing. Furthermore, analysis line method allows tolerance analysis and allocation. Ding et al. [94] proposed a process-oriented tolerancing to solve tolerance transfer issue by optimally allocating tolerances of process variables in multistation manufacturing processes. Zhou et al. [333] developed a state space approach for modelling variation propagation considering error sources in machining operations such as fixture errors, datum errors, raw part errors, machine tool errors and cutting tool errors. Nejad et al. [221] proposed the Model of Manufactured Part (MMP) method to describe positioning and machining errors at each machining setup and the different geometrical deviations using the concept of small displacement torsor (SDT).

More recently, Haghighi et al. [136] proposed a tolerance transfer method based on T-Maps [86] to model the accumulation of manufacturing errors through the different steps of the manufacturing process. At present, this method is limited to planar and cylindrical surfaces.

\subsection{Key characteristics \& process capabilities}

In a complex product, it is not economically feasible to control and/or monitor thousands of tolerances. To identify the key tolerances, many organizations are using a method called Key Characteristics (KCs). KC methods are used by design to identify and communicate to manufacturing where excess variation will most significantly affect product quality. A.C. Thornton proposes several definitions of KC [291]:

"Key Characteristics are the product, sub-assembly, part and process features that significantly impact the final cost, performance, or safety of a product when the KCs vary from nominal. Special control should be applied to those KCs where the cost of variation justifies the cost of control."

Most KC approaches are based on the concept of a KC flowdown. The KC flowdown presents a system view of potential variation risk factors and captures designers and manufacturers knowledge about variation and its contributors. A hierarchical tree structure is commonly used to describe the Key Characteristics of a product [292]. This tree structure, referred to as a KC flowdown, links customer requirements of the product to its component features (Fig. 21). A KC flowdown allows for a decomposition of the product into essential features and processes - enabling traceability of cause and effect.

Therefore, the KC flowdown allows to quantify the impact of Process KCs on Part KCs and Product KCs based on the process capability data and the variation model [207]. Cao et al. [51] describe how individual process capabilities can be rolled up to
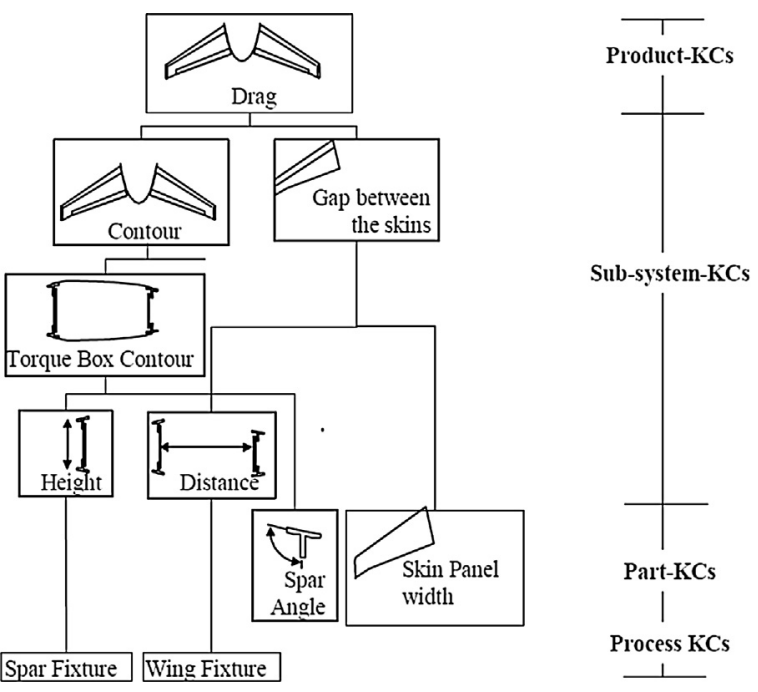

Fig. 21. KC flowdown [292]. 
provide a manufacturing performance indicator for an entire company.

The process capability approach allows for an understanding of the capability of a manufacturing resource to realize a feature and to respect the geometrical specification. Process capability data is defined as the expected and obtained standard deviations and mean shifts for a feature produced by a particular process and made of a particular material. This relationship is shown in Fig. 22.

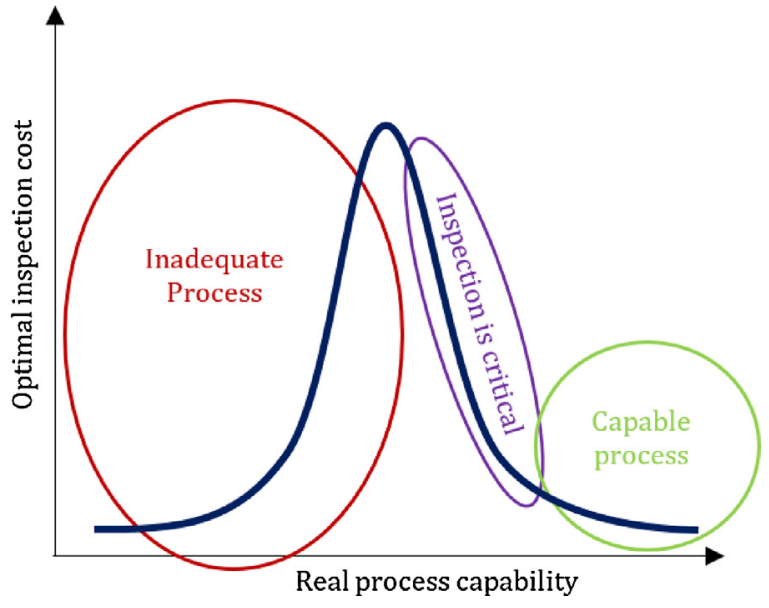

Fig. 22. Process capability vs optimal inspection cost.

\subsection{Tolerance allocation and optimization}

Tolerance allocation involves the assignment and the distribution of the values of tolerances and therefore is the inverse problem of tolerance analysis. Commonly used tolerance synthesis methods are based on specific rules of thumb for the distribution of tolerances such as equal tolerances assumption, same influence, proportional scaling, constant precision factor [96]. With respect to tolerance allocation, Hong and Chang [144] states that "Most of the tolerance allocation approaches that have been published are based on the optimization of the cost-tolerance function. They usually try to get optimal tolerance 'values' while the tolerance 'types' are assumed to be fixed. Unfortunately, however, the usage of these models in industry is fairly limited. One of the major reasons for this is that they usually try to take advantage of the superficial knowledge of processes, which is usually obtained from the machinist handbook or the company manual." This statement emphasizes the importance of the tolerance specification process, described in Section 6.1.

Among all solutions available to perform tolerance allocations, three can be distinguished:

- The first consists in equally dividing the tolerance between the workpieces achieving functional requirements (solution 1 in Fig. 23). This solution is the most straight-forward.

- The aim of the second solution is to have the same capability for all resources (solution 2 in Fig. 23) [125,292]. This solution selects only quality controlled process plan, the cost of products becomes expensive.

- Third tolerance allocation methods are based on single or multiobjective optimization of manufacturing-related functions [181,283] such as the cost of manufacturing [244,266,278], quality loss function [196], manufacturing capability [295] or any combination of these functions.

Different cost-tolerance mathematical models were developed in the literature and are mainly based on empirical cost-tolerance data $[95,149,151,179,260,279]$. In the 1970 s, various functions have

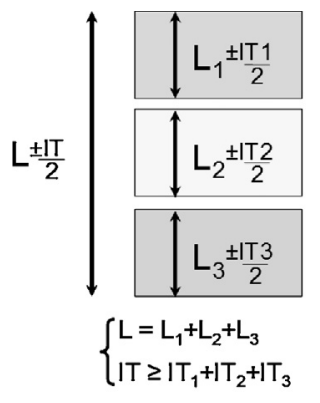

Solution 1:
\[ I T_{i}=\frac{I T}{3} \]

Solution 2 :

$$
\begin{aligned}
& C p_{i}=\frac{I T_{i}}{6 \sigma_{i}} \\
& C P_{1}=C P_{2}=C P_{3}=k \\
& I T \geq 6 \cdot k \cdot \sum_{i=1}^{3} \sigma_{i}
\end{aligned}
$$

Fig. 23. Tolerance allocation techniques.

been proposed to describe the cost-tolerance relationship:

$$
\begin{aligned}
& C_{i}\left(T_{i}\right)=a_{i}+\frac{b_{i}}{T_{i}^{K_{i}}} \\
& C_{i}\left(T_{i}\right)=\frac{b_{i}}{T_{i}^{K_{i}}} \\
& C_{i}\left(T_{i}\right)=b_{i} \cdot e^{-K_{i} \cdot T i}
\end{aligned}
$$

These models depend on many characteristics: from the workpiece material, to the kind of operation employed, to the machine or machines used in production. They are not sufficient to analyze most industrial cases, since workpieces are produced in several conditions $[187,301]$.

Several works exist proposing methodologies for the estimating the impact of this approach on the overall manufacturing costs. [111,113] have explicitly chosen an economic approach to the overall management. The global aim is the variation management during the process considering manufacturing, verification, scrap, and external failures [189,323]. The latter is the cost arising geometric inspection errors leading to customers' complaints. [41] also implicitly consider the impact of the verification in their 'value chain simulator', as quality, affected by the verification, is one of the components of the model. Most of the proposed models are based on the cost of the measurement [216,218,253,254]. In general, the typical form of a cost function for the design of a tolerance verification system is:

$C_{I}=C_{M}+C_{E}$

In which $C_{I}$ is the total cost of the inspection, $C_{M}$ is the pure cost of performing the measurement, and $C_{E}$ is the cost due to errors in inspection. The last contribution refers to the cost that who runs the inspection undergoes because of the measurement uncertainty, which reduces the conformance/nonconformance zones generating an uncertainty range, thus creating the risk of incorrect conformance statements. In general, accurate measurements are more expensive $\left(C_{M} \uparrow\right)$, but are less prone to inspection errors $\left(C_{E} \downarrow\right)$. As such, the choice of the inspection strategy is always a trade-off between accuracy and measurement costs. [218] show also that an optimal inspection planning is not always critical (Fig. 22). In fact, when the process capability is high, almost all the parts are good, and inspecting all parts is not required. Instead, one should concentrate on the design of an optimal process control $[68,69,126]$. When the capability is low, almost all parts are rejected. In this condition one should consider a redesign of the product/process (unless this is impossible - in this case, measurement is fundamental to identify the few good parts). Inspection plays a pivotal role between these two conditions. A well-designed inspection can in this case lead to significant reductions in costs. This point of view leads also to the concept of unnecessary inspection in those cases in which many tolerances are stated for a single part. In this case, one should select, based on the capability, which inspections are critical [111,214,215]. This selection of critical inspections is analogous to the identification of KCs in manufacturing processes. Mousavi et al. [219] propose a fuzzy model for the comparison of different inspection scenarios in 
terms of process monitoring and final inspection. The model anyway is not specifically addressed to inspection planning.

\subsection{Tolerance synthesis vs uncertainty}

In conclusion, tolerance synthesis, transfer and allocation was initially used for function, assembly and machining applications. The development of process-oriented tolerancing approaches especially for sheet metal parts, and compliant assemblies [7] enhances the scope of tolerancing to the product life cycle and new manufacturing processes such as additive manufacturing [5].

Tolerance synthesis is an important and specific activity for uncertainty management. In fact, the main activity of uncertainty management is the uncertainty propagation to quantify the uncertainty impact. Tolerancing is not focused solely on functionality assessment under manufacturing imperfections, but also places limits these manufacturing imperfections. To identify the best limits, the main approaches are based on the designer knowledge, the process capability assessment and the cost assessment which are affected by epistemic uncertainty (Fig. 24). Two of the main challenges are:

- to quantify and mitigate this epistemic uncertainty.

- to develop some predictive model of cost for tolerance and uncertainty management.

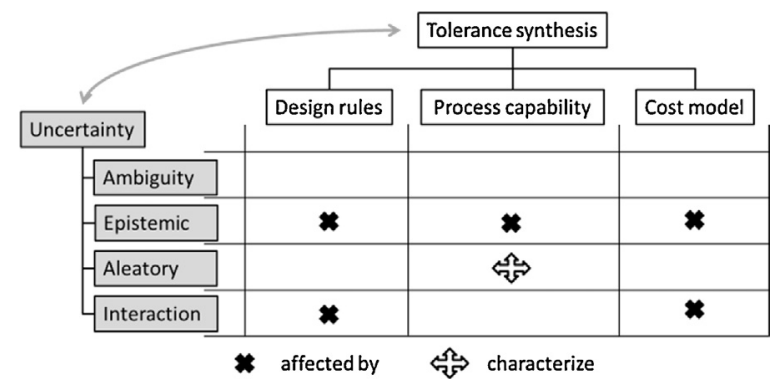

Fig. 24. Tolerance allocation vs uncertainties.

\section{New challenges}

Tolerancing has a long history of research and practice, and advances in the computational power to assist complex analyses and simulations has given the field a strong new trajectory as an integral tool in managing the product lifecycle. This chapter will address areas where unique product attributes and requirements or new manufacturing processes will stimulate additional research in variation management and - in particular - tolerancing.

\subsection{Additive manufacturing}

Global standards for additive manufacturing (AM) are already advancing through the ASTM International Technical Committee F42 on Additive Manufacturing Technologies and ISO/TC 261 Additive Manufacturing Technical Committee. ASTM has published standards on specification for AM format ISO/ASTM 52915:2013 and definition of AM terms ASTM F2792. A new ASME committee (Y14.46) was created in 2015 to consider product definition practices for additive manufacturing, including tolerances.

Current GD\&T standards (ISO TC 213 GPS and ASME Y14.5) are well established and have been developed focusing on the capabilities of traditional manufacturing processes such as machining. For AM, some efforts have been made in the past years focusing mainly on data transfer, geometry and shape specifications and definition of AM terminologies.

AM geometric specification and verification issues should address both process driven issues and capabilities issues. Process driven specification standards are in vogue for composite manufacturing, casting, forging and molding. Similarly, there is a need to develop AM process driven specification standards which can focus on AM material, manufacturing, and geometry related issues. Such issues include build direction and location, layer thickness, support structures, heterogeneous materials and scan direction [290].

AM possess excellent capabilities of producing complex surfaces and internal features. AM has also the ability to produce intricate assemblies in a single build eliminating the need of assembling individual components. For freeform surfaces specification, it is required to define the surface boundaries that need different tolerances or have non continuous tolerance zones. Moreover, with AM, produced shapes can be much closer to the results of topology optimization. For this purpose, a general surface profile specification with or without datum features indicating from variations should be investigated.

Patterns of features as discussed in ASME Y14.5 and ISO 5458 can be adopted regarding infills (non-solid support structures) governed by product function. Lattice geometries can be specified based on patterns of unit cells or more elaborate functions to model the variations of size and shape [4].

The challenges associated with specification and verification in AM are emerging [34,146,217]. New methods are necessary to communicate design intent and validate inspection plan while achieving the repeatability and the reproducibility required by AM processes and technologies in production and quality assurance. These methods must rely on tolerance representation techniques in conformance to ISO GPS standards and extend beyond current GD\&T practices $[334,335]$. For this purpose, the following issues should be addressed:

- Development of new methods to tolerance complex, freeform surfaces, heterogeneous materials and internal geometries. Complex shapes obtained by topological optimization create a new ambiguity in tolerance representation and seems therefore particularly interesting for investigation.

- Development of methods and tools to facilitate conformance assessment and tolerance verification. New inspection techniques are required to ensure that the final part meets design specification. In order to eliminate ambiguity in mapping tolerance specification to its verification, uncertainty quantification should be investigated in order to enhance inspection capabilities.

- Geometric models and data interoperability are limiting the progress of additive manufacturing. Moreover, a comprehensive geometric model for Additive Manufacturing is not mature yet. Dimensional and form accuracy and surface finish are still a bottleneck for a larger impact of AM in production and industry. Shape deviations in additive manufacturing are due to multiple variation sources such as CAD Tessellation, slicing, process variables and material properties. To improve geometric quality and interoperability and control geometric variability, the geometric deviations should be predicted, in-situ and off-line measured and integrated into the digital thread. The new developed Skin Model Shapes (SMS) paradigm enables to capture geometry and shape variability during the whole product life cycle [14]. Moreover, it is suitable for simulation and visualization. Hence, it is an instance of the digital twin concept, which is the backbone of the classical digital thread.

\subsection{Digital thread and digital twin}

The promise of the fourth industrial revolution is that product realization is supported by intelligent devices distributed throughout the manufacturing environment. Two phrases, "digital thread" and "digital twin" have been used frequently and in a variety of contexts. The digital thread is focused on the digital infrastructure - complete digital product definition, standards for interoperability, data modeling, and communication methodologies - that supports the movement of data through the product lifecycle both 
from design to final product and from deployed products back to the designer. The anticipated benefit of realizing this infrastructure is that all processes in the product lifecycle can take advantage of a traceable, authoritative data model, possibly adding information to this model. This concept of processes and products adding information to a product data model in captured in the notion of a digital twin [259]. This phrase has been used in many contexts, and has evolved from the NASA definition of "... probabilistic simulation of an as-built system ..." and can be considered as the customized analogue of a full technical data package for a product, containing additional information pertaining to a specific part, product, or process.

The presence of the digital thread and digital twin provide additional opportunities in the field of tolerancing [259,272]. With the data captured in digital twins, truly informed analysis of tolerance sensitivities can be made as this information is passed up the digital thread from actual products to the design phase. Analytical tools for tolerance analysis, which have often - to this point - operated with incomplete or inaccurate data, can be used to support the evolution of product requirements and the more effective specification of new products and services. These tools will require new standards to ensure that the context of information is captured in a predictable manner, and that the product specifications correctly flow downstream to manufacturing, inspection, and field service/maintenance operations.

\subsection{Tolerances for micro-structured geometries}

In parts whose size is scaled down to the micrometer, the standard geometric tolerances may fail in describing the functionality of the part. This is due to an inherent confusion between geometry and surfaces finish, which - at this scale - cannot be completely separated. However, operating in this size regime opens the possibility of changing and improving the characteristics of the surface in terms of optical, adhesion, and wear resistance properties. Additionally, by generating specific micro-geometric patterns on the surface, we enter the realm of "structured" surfaces. The current surface finish parameters defined in the ISO [156] and ASME [18] standards are not adequate, because they have not been developed to verify a surfaced developed to provide a specific functionality. But geometric tolerances fail as well, because, even if structured surfaces are in general constituted by repetitive patterns of well-defined geometric features, in general their actual geometry is not defined well enough to apply conventional geometric inspection policies.

To overcome these difficulties, Hartmann and Weckenmann introduced the concept of a "virtual functional gauge" [138,311,312]. The idea they propose is to completely avoid a geometric description and tolerancing of the part. The structured surface is instead directly optimized based on a simulation of the surface behavior. The verification step is based again on simulation: once the surface has been scanned by means of a 3D microscope, the functionality is verified by simulating the behavior of the real surface. The authors admit the approach is promising, but is limited by the need of effective simulation models.

A more conventional approach is proposed both by MacAulay et al. [203] and Senin et al. [265]. This approach is based on an automatic segmentation of the structured surface to identify the single constituents of the structured surface. Then each segmented constituent is verified. The authors observe that the traditional methods for tolerance definition and verification fail in describing the single constituents, and propose some new shape descriptors.

The primary challenge in the field of micro-structured surfaces is in the identification of new ways to define the functionality of the surfaces, and then to verify this functionality.

\subsection{Managing perceived quality}

In certain industries, notably the automotive industry, the perceived quality of the product or the brand can play a large role in the customer's purchase decision. The role of advertising and branding are difficult to quantify from a technical perspective, but there are factors of perceived quality that can be distilled toward technical requirements. Work by Stylidis et al. [285] has proposed an initial classification and taxonomy for perceived quality in the automotive industry that identifies Technical Perceived Quality as a subset of the broader set of Value Based Perceived Quality attributes. Numerous approaches and definitions have been used to describe perceived quality, and tend to lean toward either an aspect of the product's overall quality measure [124] or a subjective measure evoked in the customer by the product [326].

The work toward providing a complete taxonomy of perceived quality attributes without gaps or overlaps provides a foundation for additional work in this field. The Technical Perceived Quality dimensions are based on different senses by which the customer evaluates a vehicle: visual quality, feel quality, sound quality, and smell quality. The "look" of an automobile can be a highly subjective attribute, as beauty is in the eye of the beholder. The same subjectivity may apply to the exhaust note of the engine. However, road noise within the cabin is generally considered undesirable, and the study of vehicle $\mathrm{NVH}$ is mature with explicit technical requirements.

\subsection{Tolerances for freeform geometries}

Freeform surfaces have seen outstanding advances with many applications in automotive, aircraft and energy industries. Freeform surfaces are designed in a way to improve the functional specifications while meeting aesthetic requirements. Freeform surfaces are rarely described by complete explicit or implicit forms and are instead defined using parametric representations which facilitate design modification by locally controlling and modifying control points [255].

An informal definition for freeform surfaces is proposed by Campbell and Flynn, stating that such surfaces are composed of one or more non-planar and non-quadric surface patches [50]. Besl [37] states that "a free-form surface has a well-defined surface normal that is continuous almost everywhere except at vertices, edges and cusps". Savio et al. [255] classified freeform surfaces according to criteria related to their geometry and their specification. This search for a definition is to guide the considerations that must be made when it comes to planning the manufacturing and measurement of the freeform surfaces.

GPS standards define shapes according to their invariance class [167] and freeform shapes are then considered as complex shapes having no unconstrained degrees of freedom. Scott and Jiang [262] identify complex shapes as surfaces exhibiting variations in shape comprising partial geometries that can in turn be decomposed into simple features. Fang et al. [116] equivalently states that "Freeform surfaces can be defined as surfaces with no axis of rotational invariance (within or beyond the part)".

For turbine blades in particular, tolerance specifications are defined on cross-sectional profiles using GPS or GD\&T standards, and following common practices. The specification of each profile is in general independent of the others and more specifications can be required depending on the complexity of the profile and considering the environment in which it is used. Another common practice in profile specification is splitting. According to Nielsen et al. [233], aeronautics companies specify aerodynamic constraints by splitting the profile into features such as leading edge, trailing edge, pressure curve and suction curve. Then each portion of the profile is appended a tolerance specification alone.

Freeform optics are becoming increasingly popular in many industries, since they outperform the conventional optical surfaces. Axis-symmetric aspherical surfaces are well described and standardized in ISO 10110-12 [157] and tolerance specification (form) follows the practices indicated in ISO 1101 [152] and ISO 10110-5 [156], but there is still a lack of correlation between optical functions and shape parameters. A new paradigm for asphere surfaces representation is leaning towards a novel representation 
derived by Forbes [121]. Forbes' models enable an orthogonal decomposition, resulting in asphere parameters that are independent. Furthermore, design becomes easier as each parameter controls one specific aspect of the shape of the asphere and is related to a specific optical function.

\subsection{Additional applications}

As is evidenced by the new challenges in this section, there is no shortage of applications in which a better understanding of uncertainty and its sources would be a highly powerful lever with which to vastly improve both the design process and its output. In each case where a new manufacturing process is considered, there is a great deal of epistemic uncertainty in its application. The commitment to a particular new process or new material early in the design phase can pose risks because of how much is simply not known about the process. As the nature of the manufacturing process becomes better understood, the risks naturally diminish. Modeling of this evolution of risk is discussed in Refs. [261] and [104].

As more manufactured goods are used in lease or service agreements, the concept of product reliability is extended so that the objective function for design is not simply the time until failure, but the total cost including maintenance, repairs, and support. The support of agreements such as the "Contract for Availability" of a product has a broad range of epistemic uncertainty contributors, and frameworks to manage these uncertainties are beginning to be developed [107,108]. The existing work in this field may be a natural precursor to the global framework that is described in the next chapter.

\section{Conclusions \& research directions}

In this paper, the role of tolerancing in the context of the uncertainty management is revisited. Primary research topics in the field of uncertainty management are the modeling of uncertainty and technique by which the uncertainty is propagated. In the field of tolerancing, the main issues discussed here are the specification model and language, the mathematical modeling of both the geometric specification and manufacturing imperfections, tolerance synthesis, and the adaptation of the tolerancing process to new paradigms.

The mathematical modeling of geometric specifications and the modeling of uncertainty share some basic underlying concepts. The main techniques of tolerancing can be generalized to a more abstract view in uncertainty management where limits on uncertainty are managed by an allocation process, similar to that of tolerancing. This generalization is described below.

In order to ensure that the product meets its functional requirements, tolerance limits are established to bound the allowable manufacturing imperfections. For each design activity, this view can be adopted in a similar manner: the definition of tolerances in order to limit uncertainties, thereby ensuring the reliability and the robustness of that design activity. The designer may define the limits of acceptable model errors in order to ensure the accuracy of simulation or analysis results. The role of model errors is central to the concept of QMU discussed in Section 5.3, and is also addressed by new standards related to the verification and validation of computational methods [23].

Based on the concept of limiting the uncertainties in a process, the second issue is the tolerance allocation. For each step of the design process, some tolerances will need to be allocated, so that the risk due to the previously identified uncertainties can be mitigated.

Fig. 25 summarizes this global perspective of uncertainty management and the proposed new global tolerancing framework. As this structure is considered, new challenges and research opportunities are revealed:

- The definition of a language to express the limit of the ambiguity, and the definition of a scale to assess ambiguity.
- Similarly, how to express and limit epistemic uncertainty. It is possible that the concepts of Technology Readiness Levels (TRL) or knowledge management maturity models (KMMM) could be extended in this area.

- The development of techniques for ambiguity propagation as an allegory to tolerance analysis, and how to assess the impact of ambiguity on the decision making during the design process.

- The development of techniques for tolerance allocation that support not only new manufacturing processes, but also new business models and new measures of cost and risk.

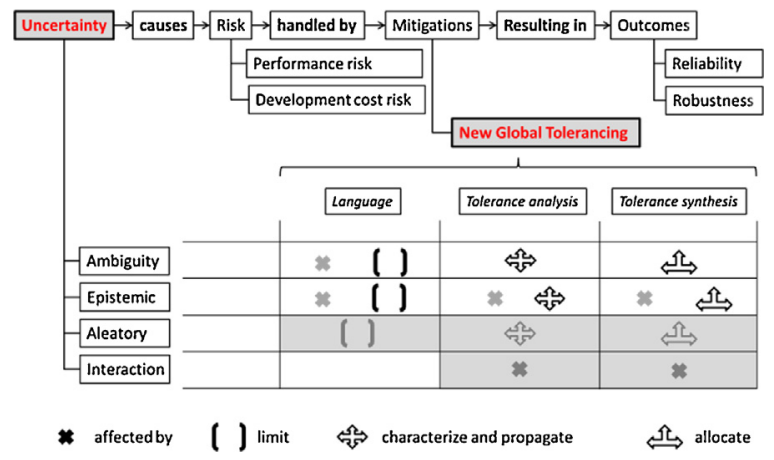

Fig. 25. A global tolerancing framework.

In addition to this new global framework, in which the idea of tolerancing is applied as a risk mitigation strategy to a wide variety of variables, the control of geometric variability will remain central to both the perceived quality and functional performance of manufactured products. The fidelity with which the variability due to manufacturing processes can be modelled, and the analytical ability to propagate this variability through multiple features, parts, or subassemblies continue to limit the success of tolerance specification, application, simulation, and verification.

As can be seen from the course of this paper, tolerancing is a mature, yet evolving field. While the early use of geometric tolerances to control geometry was constrained by primitive computational resources, the computational tolerance models used today are adequately supported by modern computers. The success of tolerance models and the tools used for tolerance propagation have helped motivate users and researchers to extend dimensional management ideas to other aspects of the product lifecycle.

\section{Acknowledgements}

The authors would like to thank the following individuals for their contributions to this work: Y. Cao (Zhejiang), J. Erkoyuncu (Cranfield), A. Etienne (LCFC), N. Gayton (SIGMA), L. Homri (LCFC), G. Lanza (KIT), S. Petrò (Polimi), W. Polini (u. Cassino), and K. Wärmefjord (Chalmers).

\section{References}

[1] Adragna P-A, Samper S, Pillet M (2009) A Proposition of 3D Inertial Tolerancing to Consider the Statistical Combination of the Location and Orientation Deviations. International Journal of Product Development 10(1-3):26-45.

[2] Allen JK, Seepersad CC, Choi H-J, Mistree F (2006) Robust Design for Multiscale, Multidisciplinary Applications. Journal of Mechanical Design 128:832-843.

[3] Ameta G, Davidson JK, Shah JJ (2007) Using Tolerance-Maps to Generate Frequency Distributions of Clearance and Allocate Tolerances for Pin-Hole Assemblies. Journal of Computing Information Science in Engineering 7(4):347359.

[4] Ameta G, Lipman R, Moylan S, Witherell P (2015) Investigating the Role of Geometric Dimensioning, Tolerancing in Additive Manufacturing. Journal of Mechanical Design 137(11):111706.

[5] Ameta G, Moylan SP, Witherell PW (2016) Challenges in Tolerances Transfer for Additive Manufacturing. ASPE Topical Meeting-Extended Abstract. 
[6] Ameta G, Samper S, Giordano M (2011) Comparison of Spatial Math Models for Tolerance Analysis: Tolerance-Maps, Deviation Domain, TTRS. Journal of Computing Information Science in Engineering 11(2):021004.

[7] Andolfatto L, Thiébaut F, Lartigue C, Douilly M (2014) Quality-and Cost-Driven Assembly Technique Selection and Geometrical Tolerance Allocation for Mechanical Structure Assembly. Journal of Manufacturing Systems 33 (1):103-115.

[8] Anselmetti B, Bourdet P (1993) Optimization of a Workpiece Considering Production Requirements. Computers in Industry 21(1):23-34.

[9] Anselmetti B, Louati H (2005) Generation of Manufacturing Tolerancing with ISO Standards. International Journal of Machine Tools and Manufacture 45 (10):1124-1131.

[10] Anselmetti B (1995) Tolerancing Method for Function and Manufacturing, ILCE 95, France.

[11] ANSI/QIF. Quality Information Framework v2.1-An Integrated Model for Manufacturing Quality Information. V 2.1: 2016: ANSI.

[12] Antonsson E, Otto K (1995) Imprecision in Engineering Design. ASME Journal of Mechanical Design 117:25-32.

[13] Anwer N, Ballu A, Mathieu L (2013) The Skin Model, A Comprehensive Geometric Model for Engineering Design. Annals of CIRP 62(1):143-146.

[14] Anwer N, Mathieu L (2016) From Reverse Engineering to Shape Engineering in Mechanical Design. Annals of CIRP 65(1):165-168.

[15] Anwer N, Schleich B, Mathieu L, Wartzack S (2014) From Solid Modelling to Skin Model Shapes: Shifting Paradigms in Computer-Aided Tolerancing. CIRP Annals-Manufacturing Technology 63(1):137-140.

[16] Armillotta A (2013) A Method for Computer-Aided Specification of Geometric Tolerances. Computer-Aided Design 45(12):1604-1616.

[18] ASME B46.1: Surface Texture (Surface Roughness, Waviness, and Lay), ASME (2009).

[19] ASME B89.4.1: Methods for Performance Evaluation of Coordinate Measuring Machines, ASME (1997)

[20] ASME B89.410360.2: Acceptance Test and Reverification Test for Coordinate Measuring Machines (CMMs)-Part 2: CMMs Used for Measuring Linear Dimensions, ASME (2008).

[21] ASME B89.4.19: Performance Evaluation of Laser-Based Spherical Coordinate Measurement Systems, ASME (2008)

[22] ASME B89.4.22: Methods for Performance Evaluation of Articulated Arm Coordinate Measuring Machines, ASME (2004).

[23] ASME V\&V 10: Guide for Verification and Validation in Computational Solid Mechanics, ASME (2006).

[24] ASME Y14.5: Dimensioning and Tolerancing, ASME (2009).

[25] ASME Y14.8: Castings, Forgings Molded Parts, ASME (2009).

[26] ASME Y14.37: Composite Part Drawings, ASME (2012).

[27] ASME Y14.5.1M: Mathematical Definition of Dimensioning and Tolerancing Principles, ASME (1994).

[28] Ayyub B, Chao R (1998) Uncertainty Modeling in Civil Engineering with Structural, Reliability Applications. Uncertainty Modeling, Analysis in Civil Engineering, CRC Press: 3-8.

[29] Ballot E, Bourdet P (2001) An Integrated Framework for 3D Tolerance Chains in Design and Manufacturing. Proceedings of DETC Vol. 1.

[30] Ballu A, Mathieu L (1993) Analysis of Dimensionnal and Geometric Specifications: Standard and Model. 3rd CIRP Seminar on Computer Aided Tolerancing, Cachan, France.

[31] Ballu A, Mathieu L (1999) Choice of Functional Specifications Using Graphs within the Framework of Education. 6th CIRP International Seminar on Computer Aided Tolerancing, Enschede, The Netherlands.

[32] Ballu A, Mathieu L, Dantan J-Y (2015) Formal Language for Geospelling. Journal of Computing Information Science in Engineering 15(2):021002021006.

[33] Ballu A, Plantec J-Y, Mathieu L (2009) Geometrical Reliability of Overconstrained Mechanisms with Gaps. Annals of the CIRP 57(1):159-162.

[34] Bartscher M, Sato O, Härtig F, Neuschaefer-Rube U (2014) Current State of Standardization in the Field of Dimensional Computed Tomography. Measurement Science and Technology 25(6):064013.

[35] Bedford T, Cooke R (2001) Different Types of Uncertainty. Probabilistic Risk Analysis: Foundations, Methods, Cambridge University Press, Cambridge, United Kingdom17-38.

[36] Bennis F, Pinos L, Fortin C (1999) Analysis of Positional Tolerance Based on the Assembly Virtual State. CIRP Seminar on Computer Aided Tolerancing, University of Twente, Netherlands.

[37] Besl Paul J (1990) The Free-Form Surface Matching Problem. in Freeman re, (Ed.) Machine Vision for Three-Dimensional Scenes, Academic Press, pp. 25-71.

[38] Bhide S, Ameta G, Davidson JK, Shah JJ (2005) Tolerance-Maps Applied to the Straightness and Orientation of an Axis. 9th CIRP International Seminar on Computer-Aided Tolerancing, Arizona State University, Tempe, AZ, USA

[39] Bhide S, Davidson J, Shah J (2003) Areal Coordinates: The Basis of a Mathematical Model for Geometric Tolerances. Geometric Product Specification, Verification: Integration of Functionality, Springer: 35-44.

[40] Bjorke O (1989) Computer-Aided Tolerancing, 2nd ed. ASME Press, New York, NY, USA.

[41] Bosch-Mauch M, Siadat A, Perry N, Bernard A (2012) VCS: Value Chains Simulator, A Tool for Value Analysis of Manufacturing Enterprise Processes (A Value-Based Decision Support Tool). Journal of Intelligent Manufacturing 23 (4):1389-1402.

[42] Bourdet P, Mathieu L, Lartigue C (1996) The Concept of the Small Displacement Torsor in Metrology. Advanced Mathematical Tools in Metrology II, Series Advances in Mathematics for Applied Sciences, World Scientific: 10-122.

[43] Browning TR (1998) Sources of Schedule Risk in Complex System Development. Proceedings of the Eighth Annual International Symposium of INCOSE.

[44] Brugnach M, Pahl-Wostl C, Lindenschmidt K, Janssen J, Filatova T, Mouton A, Holtz G, van der Keur P, Gaber N (2008) Complexity, Uncertainty: Rethinking
The Modelling Activity, U.S. Environmental Protection Agency Papers. Paper 72 .

[45] Bruyere J, Dantan JY, Bigot R, Martin P (2007) Statistical Tolerance Analysis of Bevel Gears. Mechanism and Machine Theory 42(10):1326-1351.

[46] Bruyere J, Dantan JY, Wu F, Bigot R (2006) Optimization of Gear Tolerances by Statistical Tolerances Analysis and Genetic Algorithm. 6rd IDMME Seminar, Grenoble, France.

[47] Buckingham E (1921) Principles of Interchangeable Manufacturing: A Treatise on the Basic Principles Involved in Successful Interchangeable Manufacturing Practice, Covering Design, Tolerances, Drawings, Manufacturing Equipment, Gaging, Inspection, 1st ed. Industrial Press, New York.

[48] Camelio J, Hu SJ, Ceglarek D (2003) Modeling Variation Propagation of MultiStation Assembly Systems with Compliant Parts. Journal of Mechanical Design 125(4):673-681.

[49] Camelio J, Hu SJ, Zhong W (2004) Diagnosis of Multiple Fixture Faults in Machining Processes Using Designated Component Analysis. Journal of Manufacturing Systems 23(4):309-315.

[50] Campbell RJ, Flynn PJ (2001) A Survey of Free-Form Object Representation and Recognition Techniques. Computer Vision and Image Understanding 81 (2):166-210

[51] Cao Y, Zhao K, Yang J, Xiong W (2015) Constructing the Integrated Strategic Performance Indicator System for Manufacturing Companies. International Journal of Production Research 53(13):4102-4116.

[52] Carlson JS, Spensieri D, Wärmefjord K, Segeborn J, Söderberg R (2014) Minimizing Dimensional Variation, Robot Traveling Time in Welding Station. Procedia CIRP 23:77-82.

[53] Carlson JS, Spensieri D, Söderberg R, Bohlin R, Lindkvist L (2013) NonNominal Path Planning for Robust Robotic Assembly. Journal of Manufacturing Systems 32(3):429-435.

[54] Mickaël C, Bernard A (2012) 3D ISO Manufacturing Specifications with Vectorial Representation of Tolerance Zones. The International Journal of Advanced Manufacturing Technology 60(5-8):577-588.

[55] Ceglarek D, Shi J (1997) Tolerance Analysis for Sheet Metal Assembly Using a Beam-Based Model. Proceedings Concurrent Product Design Environmentally Conscious Manufacturing.

[56] Chalupnik MJ, Wynn DC, Clarkson PJ (2009) Approaches to Mitigate the Impact of Uncertainty in Development Processes. 17th International Conference on Engineering Design, Stanford, CA, ICED'09/464.

[57] Chase KW, Parkinson AR (1991) A Survey of Research in the Application of Tolerance Analysis to the Design of Mechanical Assemblies. Research in Engineering Design 3(1):23-37.

[58] Chase KW, Gao J, Magleby SP, Sorenson C (1996) Including Geometric Feature Variations in Tolerance Analysis of Mechanical Assemblies. IIE Transactions 28 (10):795-808.

[59] Chase KW, Magleby SP, Glancy CG (1997) Tolerance Analysis of 2-D and 3-D Mechanical Assemblies with Small Kinematic Adjustments, Advanced Tolerancing Techniques, Wiley: 103-138.

[60] Chen W, Paredis C, Tumer IY (2012) Guest Editorial: Design Under Uncertainty. Journal of Mechanical Design 134:2.

[61] Cheney D, Fischer B (2015) Measuring the PMI Modeling Capability in CAD Systems: Report 1-Combined Test Case Verification. Technical Report NISTGCR15-997, NIST.

[62] Cheney D, Fischer B (2015) Measuring the PMI Modeling Capability in CAD Systems: Report 2-Combined Test Case Validation. Technical Report NISTGCR15-998.

[63] Cheney D, Fischer B (2015) Measuring the PMI Modeling Capability in CAD Systems: Report 3-Combined Test Case Validation. Technical Report NISTGCR15-999, NIST.

[64] Chevrolet Draftsman's Handbook, General Motors Corporation, Chevrolet Motor Division. Engineering Department (1940).

[65] Choi H-J (2005) A Robust Design Method for Model, Propagated Uncertainty, PhD Diss., Georgia Institute of Technology.

[66] Clement A, Riviere A, Serre P, Valade C (1999) Global Consistency of Dimensioning and Tolerancing. CIRP Seminar on Computer Aided Tolerancing, University of Twente, Netherlands.

[67] Clement A, Riviere A, Serre P, Valade C (1997) The TTRS: 13 Constraints for Dimensioning and Tolerancing. 5rd CIRP Seminar on Computer Aided Tolerancing, Toronto, Canada.

[68] Colledani M, Tolio T, Fischer A, Iung B, Lanza G, Schmitt R, Váncza J (2014) Design, Management of Manufacturing Systems for Production Quality. Annals of CIRP 63(2):773-796.

[69] Colosimo BM, Senin N (2011) Geometric Tolerances-Impact on Product Design, Quality Inspection, Statistical Process Monitoring, Springer-Verlag, London, UK.

[70] Dahlström S, Lindkvist L (2004) Variation Simulation of Sheet Metal Assemblies Using the Method of Influence Coefficients with Contact Modeling. ASME 2004 International Mechanical Engineering Congress, Exposition, Anaheim, California.

[71] Daneshkhah AR (2004) Uncertainty in Probabilistic Risk Assessment. A Review. Working Paper, University of Sheffield, UK.

[72] Dantan JY, Gayton N, Qureshi AJ, et al (2012) Tolerance Analysis Approach Based on the Classification of Uncertainty (Aleatory/Epistemic). Proceedings of the 12th CIRP Conference on Computer Aided Tolerancing, Huddersfield, UK.

[73] Dantan JY, Vincent JP, Goch G, Mathieu L (2010) Correlation UncertaintyApplication to Gear Conformity. Annals of CIRP 59(1):509-512.

[74] Dantan JY, Qureshi AJ (2009) Worst-Case, Statistical Tolerance Analysis Based on Quantified Constraint Satisfaction Problems, Monte Carlo Simulation. Computer-Aided Design 41(1):1-12.

[75] Dantan J-Y (2015) Comparison of Skin Model Representations, Tooth Contact Analysis Techniques for Gear Tolerance Analysis. Journal of Computing Information Science in Engineering 15(2). 
[76] Dantan JY, Ballu A (2002) Assembly Specification by Gauge with Interna Mobilities (GIM) - A Specification Semantics Deduced from Tolerance Synthesis. Journal of Manufacturing Systems 21(3):218-235.

[77] Dantan JY, Ballu A, Mathieu L (2008) Geometrical Product SpecificationsModel for Product Life Cycle. Computer Aided Design 40(4):493-501.

[78] Dantan JY, Bruyere J, Vincent JP, Bigot R (2008) Vectorial Tolerance Allocation of Bevel Gear by Discrete Optimization. Mechanism and Machine Theory 43 (11):1478-1494.

[79] Dantan JY, Bruyere J, Baudouin C, Bigot R (2007) Allocation of Bevel Gea Tolerances Modelling by a Vectorial Tolerancing. 10th CIRP International Seminar on Computer Aided Tolerancing, Erlangen, Allemagne.

[80] Dantan JY, Bruyere J, Baudouin C, Mathieu L (2007) Geometrical Specification of Gear: Expression and Analysis. Annals of CIRP 56(1):517-520.

[81] Dantan JY, Mathieu L, Ballu A, Martin P (2005) Tolerance Synthesis: Quantifier Notion and Virtual Boundary. Computer Aided Design 37(2):231-240.

[82] Dantan JY, Nabil A, Mathieu L (2003) Integrated Tolerancing Process for Conceptual Design. Annals of CIRP 52(1):135-138.

[83] Dantan J-Y, Qureshi AJ, Antoine J-F, Eisenbart B, Blessing LTM (2013) Management of Product Characteristics Uncertainty Based on Formal Logic, Characteristics Properties Model. Annals of CIRP 62(1):147-150.

[84] Das A, Franciosa P, Williams D, Ceglarek D (2016) Physics-Driven Shape Variation Modelling at Early Design Stage. Procedia CIRP 41:1072-1077.

[85] Davidson J, Shah J (2002) Geometric Tolerances: A New Application for Line Geometry, Screws, Part C. Journal of Mechanical Engineering Science 216 (1):95-103

[86] Davidson J, Mujezinovic A, Shah J (2002) A New Mathematical Model for Geometric Tolerances as Applied to Round Faces. Journal of Mechanical Design 124(4):609-622.

[87] De Weck O, Eckert C, Clarkson J (2007) A Classification of Uncertainty for Early Product, System Design. ICED'07-International Conference on Engineering Design, Paris, France.

[88] DeLaurentis D, Mavris D (2000) Uncertainty Modeling, Management in Multidisciplinary Analysis, Synthesis. AIAA Paper 2000-0422.

[89] Der Kiureghian A, Ditlevsen O (2009) Aleatory or Epistemic? Does it Matter? Structural Safety 31(2):105-112.

[90] Desrochers A (2007) Geometrical Variations Management in a Multi-Disciplinary Environment with the Jacobian-Torsor Model. Computer Aided Tolerancing in Design and Manufacturing 75-84.

[91] Desrochers A, Clément A (1994) A Dimensioning, Tolerancing Assistance Model for CAD/CAM Systems. The International Journal of Advanced Manufacturing Technology 9(6):352-361.

[92] Desrochers A, Ghie W, Laperriere L (2003) Application of a Unified JacobianTorsor Model for Tolerance Analysis. Journal of Computing and Information Science in Engineering 3(1):1-12.

[94] Ding YU, Jin J, Ceglarek D, Shi J (2005) Process-Oriented Tolerancing for MultiStation Assembly Systems. IIE Transactions 37(6):493-508.

[95] Diplaris SC, Sfantsikopoulos MM (2000) Cost-Tolerance Function. A New Approach for Cost Optimum Machining Accuracy. International Journal of Advanced Manufacturing Technology 16(1):32-38.

[96] Drake PJ (1999) Dimensioning and Tolerancing Handbook, McGraw-Hill, New York22-31.

[97] Dufaure J, Teissandier D, Débarbaouille G (2004) Product Model Dedicated to Collaborative Design: A Geometric Tolerancing Point of View, IDMME, Bath, UK.

[99] Durfee WF (1894) The First Systematic Attempt at Interchangeability in Fire arms, Vol. 5. Cassier's Magazine, New-York 469-477.

[100] Eastman C (1969) Cognitive Processes, Ill-Defined Problems: A Case Study from Design. Proc of the Int Joint Conf on Artificial Intelligence: IJCAI.

[101] Ebro M, Howard TJ (2016) Robust Design Principles for Reducing Variation in Functional Performance. Journal of Engineering Design 27(13):75-92.

[102] Eifler T, Christensen ME, Howard TJ (2013) A Classification of the Industrial Relevance of Robust Design Methods. 19th International Conference on Engineering Design.

[103] Eisenbart B, Khan YI, Qureshi AJ (2016) Integrated Product Modelling Through IFM-CPM/PDD. 14th International Design Conference, Cavtat, Croatia.

[104] Engelhardt R, Eifler T, Mathias J, Kloberdanz H (2011) Linkage of Methods within the Umea Methodology-An Approach to Analyse Uncertainties in the Product Development Process. 18th International Conference on Engineering Design, ICED11, Copenhagen, Denmark: Design Society.

[105] Eppinger S, Ulrich K (2015) Product Design and Development, McGraw-Hill Higher Education. ISBN: 978-0073404776.

[107] Erkoyuncu JA, Durugbo C, Shehab E, Roy R, Parker R, Gath A, Howell D (2013) Uncertainty Driven Service Cost Estimation for Decision Support at the Bidding Stage. International Journal of Production Research 51(19):5771-5788.

[108] Erkoyuncu JA, Roy R, Shehab E, Kutsch E (2014) An Innovative Uncertainty Management Framework to Support Contracting for Product-Service Availability. Journal of Service Management 25(5):603-638.

[109] Etesami F (1993) A Mathematical Model for Geometric Tolerances. Journal of Mechanical Design 115(1):81-86.

[110] Etienne A, Dantan JY, Qureshi AJ, Siadat A (2008) Variation Management by Functional Tolerance Allocation and Manufacturing Process Selection. International Journal on Interactive Design and Manufacturing 2(4):207-218.

[111] Etienne A, Dantan JY, Siadat A, Martin P (2007) Cost Estimation for Tolerance Allocation. 10th CIRP International Seminar on Computer Aided Tolerancing.

[112] Etienne A, Dantan JY, Siadat A, Martin P (2009) Activity Based Tolerance Allocation (ABTA)-Driving Tolerance Synthesis by Evaluating Its Global Cost. International Journal of Production Research 47(18):4971-4989.

[113] Etienne A, Mirdamadi S, Mohammadi M, Babaeizadeh Malmiry R, Antoine J-F Siadat A, Dantan J-Y, Tavakkoli R, Martin P (2017) Cost Engineering for Variation Management During the Product, Process Development. International Journal on Interactive Design Manufacturing 11(2):289-300.
[114] Evans DH (1974) Statistical Tolerancing: The State of the Art: Part I. Background. Journal of Quality Technology 6(4):188-195.

[115] Fainguelernt D, Weill R, Bourdet P (1986) Computer Aided Tolerancing, Dimensioning in Process Planning. CIRP Annals-Manufacturing Technology 35(1):381-386

[116] Fang FZ, Zhang XD, Weckenmann A, Zhang GX, Evans C (2013) Manufacturing and Measurement of Freeform Optics. CIRP Annals-Manufacturing Technology 62(2):823-846.

[117] Farmer LE, Gladman CA (1986) Tolerance Technology-Computer-Based Analysis. CIRP Annals-Manufacturing Technology 35(1):7-10.

[118] Feeney AB (2002) The STEP Modular Architecture. Journal of Computing Information Science in Engineering 2(2):132-135.

[119] Feeney A, Frechette S, Srinivasan V (2015) A Portrait of an ISO STEP Tolerancing Standard as an Enabler of Smart Manufacturing Systems. Journal of Computing Information Science in Engineering 15(2).

[120] Fleming A (1987) Analysis of Uncertainties and Geometric Tolerances in Assemblies of Parts, PhD Thesis, University of Edimburgh.

[121] Forbes GW (2012) Characterizing the Shape of Freeform Optics. Optics Express 20(3):2483-2499.

[122] Gao J, Chase KW, Magleby SP (1998) Generalized 3-D Tolerance Analysis of Mechanical Assemblies with Small Kinematic Adjustments. IIE Transactions 30:367-377.

[123] Gaunet D (1993) Vectorial Tolerancing Model. 3rd CIRP Seminar on Computer Aided Tolerancing, Cachan, France.

[124] Garvin DA (1984) What Does Product Quality Really Mean? Sloan Management Review 25.

[125] Gayton N, Duc E, Lemaire M (2009) The Use of Probabilistic Approach for the Tolerancing Management in Design Process. CIRP International Conference on Computer Aided Tolerancing, Annecy, France.

[126] Gerth RJ, Hancock WM (2000) Computer Aided Tolerance Analysis for Improved Process Control. Journal of Computers \& Industrial Engineering 38:1-19.

[127] Giordano M, Duret D (1993) Clearance Space and Deviation Space, Application to Three-Dimensional Chain of Dimensions and Positions. CIRP Seminar on Computer Aided Tolerancing, ENS Cachan, France.

[128] Giordano M, Adragna P-A, Germain F (2006) Taking Manufacturing Dispersions into Account for Assembly: Modelling, Simulation. Journal of Machine Engineering 6(1):83-94.

[129] Giordano M, Samper S, Petit J-P (2007) Tolerance Analysis, Synthesis by Means of Deviation Domains, Axi-Symmetric Cases, Models for Computer Aided Tolerancing in Design, Manufacturing, Springer: 85-94.

[130] Gladman C (1945) Drawing Office Practice in Relation to Interchangeable Components. Proceedings of the Institution of Mechanical Engineers 152 (1):388-418.

[131] Gramenz K (1925) Die Din passungen und ihre Anwendungen, Dinbuch 4.

[132] Garaizar OR, Anwer N, Mathieu L, Qiao L (2014) Exploring the Proceedings of Computer Aided Tolerancing CIRP Seminars and Conferences: A Scientometric Analysis. 13th CIRP Conference on Computer Aided Tolerancing (CAT 2014), 11-14 May 2014, Hangzhou, China.

[133] Grebici K, Goh YM, McMahon C (2008) Uncertainty, Risk Reduction in Engineering Design Embodiment Processes. 10th International Design Conference-Design 2008 143-156.

[134] GUM JCGM100:2008, Guide to the Expression of Uncertainty in Measurement. www.bipm.org.

[135] Gupta S, Turner JU (1993) Variational Solid Modeling for Tolerance Analysis. Journal IEEE Computer Graphics \& Application 13(3):64-74.

[136] Haghighi P, Mohan P, Shah JJ, Davidson JK (2015) A Framework for Explicating Formal Geometrical and Dimensional Tolerances Schema from Manufacturing Process Plans for Three-Dimensional Conformance Analysis. Journal of Computing and Information Science in Engineering 15(2):021003.

[138] Hartmann W, Weckenmann A (2014) Verifying the Functional Ability of Microstructured Surfaces by Model-based Testing. Measurement Science Technology 25(9)

[139] Henzold G (1993) Comparison of Vectorial Tolerancing and Conventional Tolerancing. International Forum on Dimensional Tolerancing and Metrology 27:147-160.

[140] Henzold G (2006) Geometrical Dimensioning and Tolerancing for Design, Manufacturing and Inspection-A Handbook for Geometrical Product Specification using ISO and ASME Standards, 2nd ed. Elsevier.

[141] Heysiattalab S, Morse EP (2016) From STEP to QIF: Product, Manufacturing Information. 31th ASPE Annual Meeting 65:312-317.

[142] Hillyard RC, Braid IC (1978) Characterizing Non-Ideal Shapes in Term of Dimensions and Tolerances. Computer Graphics 12(3):234-238.

[143] Hoffman P (1982) Analysis of Tolerances in Process Inaccuracies in Discrete Part Manufacturing. Computer Aided Design 14(2):83-88.

[144] Hong YS, Chang TC (2002) A Comprehensive Review of Tolerancing Research. International Journal of Production Research 40:2425-2459.

[146] Huang Q Nouri H, Xu K, Chen Y, Sosina S, Dasgupta T (2014) Statistical Predictive Modeling, Compensation of Geometric Deviations of Three-Dimensional Printed Products. Journal of Manufacturing Science and Engineering 136(6):061008

[147] Huang W, Ceglarek D (2002) Mode-Based Decomposition of Part Form Error by Discrete-Cosine-Transform with Implementation to Assembly, Stamping System with Compliant Parts. Annals of CIRP 51(1):21-26.

[148] Humienny Z (2009) State of Art in Standardization in GPS Area. CIRP Journal of Manufacturing Science Technology 2(1):1-7.

[149] Iannuzzi MP, Sandgren E (1995) Tolerance Optimization Using Genetic Algorithms: Benchmarking with Manual Analysis. 4th CIRP Design Seminar on Computer-Aided Tolerancing.

[150] INCOSE Systems Engineering Handbook, Version 2.0, (2000), International Council on Systems Engineering (INCOSE). 
[151] Irani SA, Mittal RO, Lehtihet EA (1989) Tolerance Chart Optimization. International Journal of Production Research 27(9):1531-1552.

[152] ISO 1101:2017, Geometrical Product Specifications (GPS) - Geometrical Tolerancing - Tolerances of Form, Orientation, Location and Run-out.

[153] ISO 10360-2:1994, Geometrical product specifications (GPS) - Acceptance, reverification tests for coordinate measuring machines (CMM).

[154] ISO 5458:1998, Geometrical Product Specifications (GPS) - Geometrical Tolerancing - Positional Tolerancing.

[155] ISO 15530:2004, Geometrical Product Specifications (GPS) - Coordinate measuring machines (CMM): Technique for determining the uncertainty of measurement.

[156] ISO 10110-5:2007, Optics and Photonics - Preparation od drawings for optical elements and systems, Part 5: Surface form tolerances.

[157] ISO 10110-12:2007, Optics and Photonics - Preparation of drawings for optical elements and systems, Part 12: Aspheric surfaces.

[158] ISO 12180-1:2011, Geometrical Product Specifications (GPS) - Cylindricity Part 1: Vocabulary, parameters of cylindrical form.

[159] ISO 12180-2:2011, Geometrical Product Specifications (GPS) - Cylindricity Part 2: Specification operators.

[160] ISO 12181-1:2011 Geometrical Product Specifications (GPS) - Roundness Part 1: Vocabulary, parameters of roundness.

[161] ISO 12181-2:2011, Geometrical Product Specifications (GPS) - Roundness Part 2: Specification operators.

[162] ISO 12780-1:2011, Geometrical Product Specifications (GPS) - Straightness Part 1: Vocabulary, parameters of straightness.

[163] ISO 12780-2:2011, Geometrical Product Specifications (GPS) - Straightness Part 2: Specification operators.

[164] ISO 12781-1:2011, Geometrical Product Specifications (GPS) - Flatness - Part 1: Vocabulary, parameters of Flatness.

[165] ISO 12781-2:2011, Geometrical Product Specifications (GPS) - Flatness - Part 2: Specification operators.

[166] ISO 14253-2:2011, Geometrical Product Specifications (GPS) - Inspection by measurement of workpieces, measuring equipment - Part 2: Guidance for the estimation of uncertainty in GPS measurement, in calibration of measuring equipment, in product verification.

[167] ISO 17450-1:2011, Geometrical product specifications (GPS) - General concepts - Part 1: Model for geometrical specification, verification.

[168] ISO 8015:2011, Geometrical product specifications (GPS) - Fundamentals Concepts, principles, rules.

[169] ISO 17450-2:2012, Geometrical product specifications (GPS) - General concepts - Part 2: Basic tenets, specifications, operators, uncertainties and ambiguities.

[170] ISO 14253-1:2013, Geometrical product specifications (GPS) - inspection by measurement of workpieces and measuring equipment - part 1: Decision rules for proving conformance or nonconformance with specifications.

[171] ISO 10303-242:2014, Industrial automation systems and integration - Product data representation and exchange - Part 242: Application protocol: Managed model-based 3D engineering - First edition; Includes Access to Additional Content.

[172] ISO 14638:2015, Geometrical product specifications (GPS) - Matrix model

[173] ISO/DIS 8062-4.2:2015, Geometrical product specifications (GPS) - Dimensional and geometrical tolerances for moulded parts - Part 4: General tolerances for castings using profile tolerancing in a general datum system.

[174] ISO 14405-1:2016, Geometrical product specifications (GPS) - Dimensional tolerancing - Part 1: Linear sizes.

[175] Jareteg C, Wärmefjord K, Söderberg R, Lindkvist L, Carlson JS, Cromvik C, Edelvik F (2014) Variation Simulation for Composite Parts, Assemblies Including Variation in Fiber Orientation, Thickness, CIRP CATS 2014.

[176] Jian A, Ameta G, Davidson J, Shah J (2007) Tolerance Analysis, Allocation Using Tolerance-Maps for a Power Saw Assembly. Models for Computer Aided Tolerancing in Design, Manufacturing, Springer: 267-276.

[177] Jiang XJ, Whitehouse DJ (2012) Technological Shifts in Surface Metrology. CIRP Annals-Manufacturing Technology 61(2):815-836.

[178] Johannesson H, Söderberg R (2000) Structure and Matrix for Tolerance Analysis from Configuration to Detail Design. Research in Engineering Design $12: 112-125$.

[179] Johnson HT, Kaplan RS (1987) Relevance Cost, the Rise and Fall of Management Accounting, Harvard Business School Press.

[180] Joskowicz L, Sacks E, Srinivasan V (1997) Kinematic Tolerance Analysis. Computer Aided Design 29(2):147-157.

[181] Karmakar S, Maiti J (2012) A Review on Dimensional Tolerance Synthesis: Paradigm Shift from Product to Process. Assembly Automation 32(4):373-388.

[182] Kharoufeh JP, Chandra MJ (2002) Statistical Tolerance Analysis for NonNormal or Correlated Normal Component Characteristics. International Journal of Production Research 40(2):337-352.

[183] Klir G, Folger T (1988) Types of Uncertainty. Fuzzy Sets, Uncertainty, Information, Prentice Hall, Englewood Cliffs, NJ138-139.

[184] Kreye ME, Goh YM, Newnes LB (2011) Manifestation of Uncertainty-A Classification. 18th International Conference on Engineering Design 6:96-107.

[185] Krogstie L, Gaarder A, Andersen B (2014) Variation Analysis in Collaborative Engineering; An Industrial Case Study of Rocket Motor Development. Procedia CIRP 21:306-311.

[186] Kunzmann H, Pfeifer T, Schmitt R, Schwenke H, Weckenmann A (2005) Productive Metrology-Adding Value to Manufacture. Annals of CIRP 54 (2):155-168.

[187] Lanza G, Haefner B, Kraemer A (2015) Optimization of Selective Assembly and Adaptive Manufacturing by Means of Cyber-Physical System Based Matching. CIRP Annals-Manufacturing Technology 64(1):399-402.

[189] Legoff O, Tichadou S, Hascoet JY (2005) Manufacturing Errors Modelling: Two Three-Dimensional Approaches. Part B-Journal of Engineering Manufacture 218:1869-1873.
[190] Linares JM, Anthierens C, Sprauel JM (2002) Synthesis of Tolerancing by Functional Group. Journal of Manufacturing Systems 21(4):260-275.

[191] Lindau B, Wärmefjord K, Lindkvist L, Söderberg R (2014) Method for Handling Model Growth in Nonrigid Variation Simulation of Sheet Metal Assemblies. Journal of Computing and Information Science in Engineering 14(3):031004.

[192] Lindau B, Lindkvist L, Andersson A, Söderberg R (2013) Statistical Shape Modeling in Virtual Assembly Using PCA-Technique. Journal of Manufacturing Systems 32(3):456-463.

[193] Lindau B, Lorin S, Lindkvist L, Söderberg R (2016) Efficient Contact Modeling in Nonrigid Variation Simulation. Journal of Computing and Information Science in Engineering 16(1):011002.

[194] Lipman R, Lubell J (2015) Conformance Checking of PMI Representation in Cad Model Step Data Exchange Files. Computer Aided Design 66:14-23.

[195] Liu SC, Hu SJ (1997) Variation Simulation for Deformable Sheet Metal Assemblies Using Finite Element Methods. Journal of Manufacturing Science Engineering 119:68-374.

[196] Lööf J, Hermansson T, Söderberg R (2005) An Efficient Solution to the Discrete Least-Cost Tolerance Allocation Problem with General Loss Functions. 9th CIRP International Seminar on Computer Aided Tolerancing, Tempe, Arizona, USA.

[197] Loose JP, Zhou SY, Ceglarek D (2007) Kinematic Analysis of Dimensional Variation Propagation for Multistage Machining Processes with General Fixture Layouts. IEEE Transactions on Automation Science and Engineering 4:141-152.

[198] Lorin S, Lindkvist L, Söderberg R (2012) Simulating Part and Assembly Variation for Injection Molded Parts. ASME 2012 International Design Engineering Technical Conferences, Computers and Information in Engineering Conference, American Society of Mechanical Engineers.

[199] Lorin S, Lindkvist L, Söderberg R, Sandboge R (2012) Combining Variation Simulation with Thermal Expansion for Geometry Assurance. ASME 2012 International Design Engineering Technical Conferences, Computers, Information in Engineering Conference, American Society of Mechanical Engineers.

[200] Lu W, Liu X, Jiang X, Xu Z (2008) Research on Specification Uncertainty in the Next Generation GPS. Key Engineering Materials 381:561-564.

[201] Lundgren M, Hedlind M, Kjellberg T (2015) Model-Driven Process Planning and Quality Assurance. 9th CIRP Conference on Intelligent Computation in Manufacturing Engineering-CIRP ICME'14 33:209-214.

[202] Lundgren M, Hedlind M, Kjellberg T (2016) Model Driven Manufacturing Process Design and Managing Quality. 26th CIRP Design Conference 50:299304.

[203] MacAulay GD, Senin N, Giusca CL, Leach RK, Ivanov A (2015) Review of Feature Boundary Identification Techniques for the Characterization of Tessellated Surfaces. Surface Topography: Metrology and Properties 3(1):013002.

[204] Malmiry RB, Pailhès J, Qureshi AJ, Antoine JF, Dantan JY (2016) Management of Product Design Complexity Due to Epistemic Uncertainty via Energy Flow Modelling Based on CPM. Annals of CIRP 65(1):169-172.

[205] Mansoor EM (1963) The Application of Probability to Tolerances Used in Engineering Designs. Proceedings of the Institution of Mechanical Engineers 178 (1):29-39.

[206] Mantripragada R, Whitney DE (1998) The Datum Flow Chain: A Systematic Approach to Assembly Design and Modeling. Research in Engineering Design 10(3):150-165

[207] Marguet B, Mathieu L (2001) Integrated Design Method to Improve Producibility Based on Product Key Characteristics and Assembly Sequences. Annals of the CIRP 50(1):85-91.

[208] Mathieu L, Ballu A (2003) GEOSPELLING: A Common Language for Specification and Verification to Express Method Uncertainty. Proc of 8th CIRP Seminar on Computer Aided Tolerancing 28-29.

[209] McManus H, Hastings D (2005) A Framework for Understanding Uncertainty and Its Mitigation, Exploitation in Complex Systems. INCOSE International Symposium 15(1):484-503.

[210] Mejbri H, Anselmetti B, Mawussi K (2005) Functional Tolerancing of Complex Mechanisms: Identification and Specification of Key Parts. Computers \& Industrial Engineering 49(2):241-265.

[211] Melchers R (1999) Uncertainties in Reliability Assessment. Structural Reliability Analysis and Prediction, John Wiley \& Sons, Chichester, United Kingdom3445.

[212] Messac A, Ismail-Yahaya A (2002) Multiobjective Robust Design Using Physical Programming. Structural and Multidisciplinary Optimization 23(5):357371.

[213] Mistree F, Smith W, Bras B, Allen J, Muster D (1990) Decision-Based Design: A Contemporary Paradigm for Ship Design Transactions. Society of Naval Architects and Marine Engineers 98:565-597.

[214] Mohammadi M, Siadat A, Dantan J-Y, Tavakkoli-Moghaddam R (2015) Mathematical Modelling of a Robust Inspection Process Plan: Taguchi, Monte Carlo Methods. International Journal of Production Research 53(7):2202-2224.

[215] Moroni G, Petrò S (2013) Inspection Strategies, Multiple Geometric Tolerances. Procedia CIRP 10:54-60.

[216] Moroni G, Petrò S (2014) Optimal Inspection Strategy Planning for Geometric Tolerance Verification. Precis Engineering 38(1):71-81.

[217] Moroni G, Petrò S, Polini W (2017) Geometrical Product Specification, Verification in Additive Manufacturing. Annals of CIRP 157-160.

[218] Moroni G, Petrò S, Tolio T (2011) Early Cost Estimation for Tolerance Verification. Annals of CIRP 60(1):195-198.

[219] Mousavi S, Mirdamadi S, Siadat A, Dantan J, Tavakkoli-Moghaddam R (2015) An Intuitionistic Fuzzy Grey Model for Selection Problems with an Application to the Inspection Planning in Manufacturing Firms. Engineering Applications of Artificial Intelligence 39:157-167.

[220] Mujezinovice A, Davidson J, Shah J (2004) A New Mathematical Model for Geometric Tolerances as Applied to Polygonal Faces. Journal of Mechanical Design 126(3):504-518. 
[221] Nejad MK, Vignat F, Villeneuve F (2009) Simulation of the Geometrica Defects of Manufacturing. The International Journal of Advanced Manufacturing Technology 45(7-8):631-648.

[222] Nielsen HS (2006) New Concepts in Specifications, Operators and Uncertainties and Their Impact on Measurement and Instrumentation. Measurement Science and Technology 17(3):541.

[223] Nielsen HS (2013) Recent Developments in International Organization for Standardization Geometrical Product Specification Standards, Strategic Plans for Future Work. Proceedings of the Institution of Mechanical Engineers Part B: Journal of Engineering Manufacture 227(5):643-649.

[224] Nigam SD, Turner JU (1995) Review of Statistical Approaches to Tolerance analysis. Computer Aided Design 27(1):6-15.

[225] Oberkampf W, Helton J, Joslyn C, Wojtkiewicz S, Ferson S (2004) Challenge Problems: Uncertainty in System Response Given Uncertain Parameters. Reliability Engineering \&' System Safety 85(1-3):11-19.

[226] Oberkampf W, Helton J, Sentz K (2001) Mathematical Representation of Uncertainty. AIAA Paper 2001-1645.

[227] Otto K (1992) A Formal Representational Theory for Engineering Design. Doctoral Dissertation, California Inst. of Technology, Department of Mechanical Engineering.

[228] Otto K, Antonsson E (1993) Extensions to the Taguchi Method of Product Design. Journal of Mechanical Design 115(1):5-13.

[229] Otto K, Antonsson E (1994) Design Parameter Selection in the Presence of Noise. Research in Engineering Design 6(4):234-246.

[230] Parker S (1940) Notes on Design and Inspection of Mass Production Engineering Work, Gauge Design Drawing Office, Naval Ordnance Gauge Factory, Sheffield, Sheffield, UK

[231] Peak RS, Lubell J, Srinivasan V, Waterbury SC (2005) STEP, XML, and UML: Complementary Technologies. Journal of Computing and Information Science in Engineering 4(4):379-390.

[232] Peters J, Bryan J, Estler W, Evans C, Kunzmann H, Lucca D, Sartori S, Sato H, Thwaite E, Vanherck P, Hocken R, Peklenik J, Pfeifer T, Trumpold H, Vorburge T (2001) Contribution of CIRP to the Development of Metrology and Surface Quality Evaluation During the Last Fifty Years. CIRP Annals 50(2):471-488.

[233] Petitcuenot M, Pierre L, Anselmetti B (2015) ISO Specifications of Complex Surfaces: Application on Aerodynamic Profiles. Procedia CIRP 27:16-22.

[234] Polini W, Moroni G (2015) Manufacturing Signature for Tolerance Analysis Journal of Computing and Information Science in Engineering 15(2):021005.

[236] Qi Q Jiang X, Scott PJ, Lu W (2013) Surface Texture Specification, the More Complete the Better? Procedia CIRP 10:233-237.

[237] Qureshi AJ (2011) Contributions à la maîtrise de la robustesse des produits: Formalisation par logique formelle, applications à la conception ensembliste et au tolérancement, PhD diss., Arts et Métiers ParisTech, Paris.

[238] Qureshi AJ, Gericke K, Blessing L (2014) Stages in Product Lifecycle: TransDisciplinary Design Context. Procedia CIRP 21:224-229.

[239] Qureshi J, Dantan J-Y, Bruyere J, Bigot R (2009) Tolerance Analysis Based on Quantified Constraint Satisfaction Problems. 11th CIRP International Seminar on Computer Aided Tolerancing, Annecy, France.

[240] Ranieri C (1946) Il problema delle tolleranze nel funzionamento e nella costruzione di complessi meccanici da realizzare in grandi serie. Unica opera completa ad uso delle ditte costruttrici, dei disegnatori, Hoepli, Milano.

[241] Remmerswaal J., with CIRP, 1991, Forty Years of CIRP: The History of the International Institution for Production Engineering Research; 1951-1991.

[242] Requicha AAG (1983) Toward a Theory of Geometric Tolerancing. International Journal of Robotics Research 2(4):45-60.

[244] Ricci F, Scott PJ, Jiang X (2013) A Categorical Model for Uncertainty and Cost Management within the Geometrical Product Specification (GPS) Framework. Precision Engineering 37(2):265-274.

[245] Rivest L, Fortin C, Morel C (1993) Tolerancing a Solid Model with a Kinematic Formulation. Proceedings on the Second ACM Symposium on Solid Modeling and Applications ACM

[246] Robinson DM (1997) Geometric Tolerancing for Assembly with Maximum Material Parts. Proc. of 5rd CIRP Seminar on Computer Aided Tolerancing, Toronto; Canada; April 27-29.

[247] Robinson DM (1998) Geometric Tolerancing for Assembly, PhD Thesis, Cornell University.

[248] Roy CJ, Oberkampf WL (2011) A Comprehensive Framework for Verification, Validation, and Uncertainty Quantification in Scientific Computing. Computer Methods in Applied Mechanics and Engineering 200(25-28):2131-2144.

[249] Roy U, Pramanik N, Sudarsan R, Sriram RD, Lyons KW (2001) Function to Form Mapping: Model, Representation and Application in Design Synthesis. Computer Aided Design 33:699-719.

[250] Sacks E, Joskowicz L (1997) Parametric Kinematic Tolerance Analysis of Planar Mechanisms. Computer Aided Design 29(5):333-342.

[251] Samper S, Petit J-P, Giordano M (2006) Computer Aided Tolerancing-Solver Post Processor Analysis. Advances in Design, Springer: 487-497.

[252] Samper S, Petit J-P, Giordano M (2007) Elastic Clearance Domain and Use Rate Concept Applications to Ball Bearings and Gears. Models for Computer Aided Tolerancing in Design and Manufacturing, Springer: 331-340.

[253] Savio E (2012) A Methodology for the Quantification of Value-Adding by Manufacturing Metrology. Annals of CIRP 61(1):503-506.

[254] Savio E, De Chiffre L, Carmignato S, Meinertz J (2016) Economic Benefits of Metrology in Manufacturing. Annals of CIRP 65(1):495-498.

[255] Savio E, De Chiffre L, Schmitt R (2007) Metrology of Freeform Shaped Parts. CIRP Annals-Manufacturing Technology 56(2):810-835.

[256] Schleich B, Wartzack S (2015) A Generic Approach to Sensitivity Analysis in Geometric Variations Management. 20th International Conference on Engineering Design 4:343-352.

[257] Schleich B, Wartzack S (2015) Evaluation of Geometric Tolerances and Generation of Variational Part Representatives for Tolerance Analysis. Inter national Journal of Advanced Manufacturing Technology 79(5-8):959-983.
[258] Schleich B, Anwer N, Mathieu L, Wartzack S (2014) Skin Model Shapes: A New Paradigm Shift for Geometric Variations Modelling in Mechanical Engineering. Computer-Aided Design 50:1-15.

[259] Schleich B, Anwer N, Mathieu L, Wartzack S (2017) Shaping the Digital Twin for Design and Production Engineering. Annals of CIRP 66(1):141-144.

[260] Schmitt R, Behrens C (2007) A Statistical Method for Analyses of Cost- and Risk Optimal Tolerance Allocations Based on Assured Input Data. 10th CIRP International Seminar on Computer Aided Tolerancing, Erlangen, Allemagne.

[261] Schwabe O, Shehab E, Erkoyuncu J (2015) Uncertainty Quantification Metrics for Whole Product Life Cycle Cost Estimates in Aerospace Innovation. Progress in Aerospace Sciences 77:1-24

[262] Scott PJ, Jiang X (2014) Freeform Surface Characterisation: Theory and Practice. Journal of Physics: Conference Series 483(1):012005. IOP Publishing.

[263] Segeborn J, Torstensson J, Carlson JS, Söderberg R (2010) Evaluating Genetic Algorithms that Optimize Welding Sequence with Respect to Geometrical Assembly Variation, Design 2010 Conference, August 25-27, Gothenburg, Sweden.

[264] Sellakh R, Riviere A, Chevassus N, Marguet B (2001) An Assisted Method for Specifying ISO Tolerances Applied to Structural Assemblies. CIRP Seminar on Computer Aided Tolerancing, France.

[265] Senin Nicola, Thompson Adam, Leach Richard K (2017) Feature-Based Characterisation of Laser Powder Bed Fusion Surfaces. Proc. Joint Special Interest Group Meeting Between EUSPEN and ASPE Dimensional Accuracy and Surface Finish in Additive Manufacturing, 10-12 October 2017, Leuven, Belgium.

[266] Shan A, Roth RN (2003) Genetic Algorithms in Statistical Tolerancing. Journal of Mathematical and Computer Modeling 38:1427-1436.

[267] Shen Z, Ameta G, Shah J (2005) A Comparative Study of Tolerance Analysis Methods. Journal of Computing and Information Science in Engineering 5:247256.

[268] Singh G, Ameta G, Davidson J, Shah J (2009) Worst-Case Tolerance Analysis of a Self-Aligning Coupling Assembly Using Tolerance-Maps. 11th CIRP International Conference on Computer Aided Tolerancing, Annecy, France.

[269] Skowronski VJ, Turner JU (1996) Estimating Gradients for Statistical Tolerance Synthesis. Computer-Aided Design 28(12):933-941.

[270] Skowronski VJ, Turner JU (1997) Using Monte Carlo Variance Reduction in Statistical Tolerance Synthesis. Computer-Aided Design 29(1):63-69.

[271] Söderberg R (1998) Robust Design by Support of CAT Tools. ASME Design Automation Conference, Atlanta, USA, DETC 98/DAC-5633.

[272] Söderberg R, Wärmefjord K, Carlson JS, Lindkvist L (2017) Toward a Digital Twin for Real-Time Geometry Assurance in Individualized Production. Annals of CIRP 66(1):137-140.

[273] Söderberg R, Wärmefjord K, Lindkvist L (2015) Variation Simulation of Stress During Assembly of Composite Parts. CIRP Annals 64(1):17-20.

[274] Söderberg R, Wärmefjord K, Lindkvist L, Berlin R (2012) The Influence of Spot Weld Position Variation on Geometrical Quality. Annals of CIRP 61(1):13-16.

[275] Söderberg R, Lindkvist L (1999) Computer Aided Assembly Robustness Evaluation. Journal of Engineering Design 10(2):165-181.

[276] Söderberg R, Lindkvist L, Carlson J (2006) Virtual Geometry Assurance for Effective Product Realization. 1st Nordic Conference on Product Lifecycle Management-NordPLM'06, Göteborg, Sweden.

[277] Söderberg R, Lindkvist L, Carlson JS (2006) Managing Physical Dependencies Through Location System Design. Journal of Engineering Design 17(4):325346

[278] Speckhart FH (1972) Calculation of Tolerance Based on Minimum Cost Approach. Journal of Engineering for Industry Transactions of ASME 94:447453.

[279] Spotts MF (1973) Allocation of Tolerances to Minimize Cost of Assembly. Journal of Engineering for Industry Transactions of the ASME 95:762-864.

[280] Srinivasan V (2003) An Integrated View of Geometrical Product Specification, Verification. Geometric Product Specification, Verification: Integration of Functionality, Springer, Dordrecht1-11.

[281] Srinivasan V (2007) Computational Metrology for the Design and Manufacture of Product Geometry: A Classification and Synthesis. Journal of Computing and Information Science in Engineering 7(1):3-9.

[282] Srinivasan V (2008) Standardizing the Specification, Verification, Exchange of Product Geometry: Research, Status, Trends. CAD Computer Aided Design 40 (7):738-749.

[283] Srinivasan RS, Wood KL, McAdams DA (1996) Functional Tolerancing: A Design for Manufacturing Methodology. Research in Engineering Design 8:99-115.

[284] Srinivasan V, Jayaraman R (1989) Conditional Tolerances. IBM Journal of Research and Develpment 33(2):105-124

[285] Stylidis K, Wickman C, Söderberg R (2015) Defining Perceived Quality in the Automotive Industry: An Engineering Approach. Procedia CIRP 36:165-170

[287] Taylor W. (1905) Improvements in gauges for screws, British Patent no. 6900

288] Teissandier D, Delos V Couétard Y (1999) Operations on Polytopes: Application to Tolerance Analysis. 6th CIRP International Seminar on Computer-Aided Tolerancing, Enschede, The Netherlands.

[289] Thomas TR (2013) Roughness and Function. Surface Topography: Metrology and Properties 2(1):014001.

[290] Thompson M, Moroni G, Vaneker T, Fadel G, Campbell R, Gibson I, Bernard A, Schulz J, Graf P, Ahuja B, Martina F (2016) Design for Additive Manufacturing: Trends, Opportunities, Considerations, Constraints. Annals of CIRP 65(2):737-760.

[291] Thornton AC, Tata M (1999) Process Capability Database Usage in Industry: Myth vs Reality. ASME Design Engineering Technical Conferences.

[292] Thornton AC (1999) Variation Risk Management Using Modeling and Simulation. Journal of Mechanical Design 121:297-304.

[293] Thunnissen DP (2005) Propagating, Mitigating Uncertainty in the Design of Complex Multidisciplinary Systems, California Institute of Technology.

[294] Thunnissen DP (2003) Uncertainty Classification for the Design, Development of Complex Systems. 3rd Annual Predictive Methods Conference, Newport Beach, California, 1-16. 
[295] Tsai JC, Cheng KC (2005) Cost-Effective Tolerance Allocation for Machining Processes. 9th CIRP International Seminar on Computer Aided Tolerancing, Tempe, Arizona, USA.

[296] Varghese P, Braswell N (1996) Statistical Tolerance Analysis Using FRPDF and Numerical Convolution. Computer Aided Design 28(9):723-732.

[298] Vincent JP, Dantan JY, Bigot R (2009) Virtual Meshing Simulation for Gear Conformity Verification. CIRP Journal of Manufacturing Science Technology 2 (1):35-46.

[299] Voelcker HB (1998) The Current State of Affairs in Dimensional Tolerancing. Integrated Manufacturing Sytems 9:205-217.

[300] Wagersten O, Lindau B, Lindkvist L, Söderberg R (2014) Using Morphing Techniques in Early Variation Analysis. Journal of Computing Information Science in Engineering 14(1):011007.

[301] Wagner R, Haefner B, Lanza G (2016) Pairing Strategies for High-Precision Products-Industrie 4.0 Provides Opportunities to Produce at Low Cost While Meeting Groqing Demands for Product Precision. wt Werkstatttechnik online 106(11-12):804-808.

[302] Walter M, Storch M, Wartzack S (2014) On Uncertainties in Simulations in Engineering Design: A Statistical Tolerance Analysis Application. Simulation Transactions of the Society for Modeling and Simulation International 90 (5):547-559

[303] Wang JX, Jiang X, Ma L, Xu Z, Li Z (2006) Decision Rules for Workpieces Based on Total Uncertainty. The International Journal of Advanced Manufacturing Technology 28(11-12):1169-1174.

[304] Wang J, Ma L, Jiang X, Xu Z, Li Z (2004) A Framework for Uncertainty Evaluation of GPS Standard-Chain. Proc ASPE 2004 Summer Topical Meeting on Uncertainty Analysis in Measurement Design 146-151.

[305] Wang MY, Pelinescu DM (2001) Optimizing Fixture Layout in a Point-Set Domain. IEEE Transactions on Robotics and Automation 17(3):312-323.

[306] Wärmefjord K, Lindau B, Lindkvist L, Lorin S (2016) Joining in Nonrigid Variation Simulation. Computer-aided Technologies - Applications in Engineering and Medicine, . http://dx.doi.org/10.5772/65851.

[307] Wärmefjord K (2011) Variation Control in Virtual Product Realization-A Statistical Approach, Chalmers University of Technology.

[308] Wärmefjord K, Söderberg R, Lindkvist L (2008) Tolerance Simulation of Compliant Sheet Metal Assemblies Using Automatic Node-Based Contact Detection. IMECE2008, Boston, USA.

[309] Wärmefjord K, Söderberg R, Lindkvist L (2013) Simulation of the Effect of Geometrical Variation on Assembly, Holding Forces. International Journal of Product Development 18(1):88-108.

[310] Wärmefjord K, Söderberg R, Lindkvist L (2010) Strategies for Optimization of Spot Welding Sequence with Respect to Geometrical Variation in Sheet Metal Assemblies. ASME International Mechanical Engineering Congress E'Exposition, Vancouver, Canada.

[311] Weckenmann A, Hartmann W (2013) Function-Oriented Method for the Definition and Verification of Microstructured Surfaces. Precision Engineering 37(3):684-693.

[312] Weckenmann A, Hartmann W (2015) A Model-, Simulation-Based Approach for Tolerancing and Verifying the Functional Capability of Micro/Nano-Structured Workpieces. Measurement 76:70-79.

[313] Weill RD (1997) The CIRP Computer-Aided Tolerancing Seminars-A Historical Perspective. Proceedings of the 5th CIRP International Seminar on Computer Aided Tolerancing, Toronto, Ontario, Canada.

[314] Weill RD, Clément A, Hocken R, Farmer LE, Gladman CA, Wirtz A, Bourdet P, Freckleton JE, Kunzmann H, Ham I, Trumpold H, Matthias E (1988) Tolerancing for Function. CIRP Annals-Manufacturing Technology 37(2):603-610.
[315] Whitehouse DJ (1982) The Parameter Rash-Is There a Cure? Wear 83(1):7578.

[316] Whitehouse DJ (2001) Function Maps and the Role of Surfaces. International Journal of Machine Tools and Manufacture 41(13-14):1847-1861.

[317] Whitney DE (2004) Mechanical Assemblies: Their Design Manufacture and Role in Product Development, Vol. 1. Oxford University Press, New York.

[318] Wilhelm RG, Hocken R, Schwenke H (2001) Task Specific Uncertainty in Coordinate Measurement. CIRP Annals 50(2):553-563.

[319] Wirtz A (1991) Vectorial Tolerancing for Production Quality Control and Functional Analysis in Design. 2nd CIRP conference on Computer-Aided Tolerancing, 77-84.

[321] Witherell P, Herron J, Ameta G (2016) Towards Annotations and Product Definitions for Additive Manufacturing. 14th CIRP Conference on Computer Aided Tolerancing 43:339-344.

[322] Witherell P, Herron J, Ameta G (2016) Towards Annotationsn and Product, Definitions for Additive Manufacturing. Procedia CIRP 43:339-344.

[323] Wu F, Dantan JY, Etienne A, Siadat A, Martin P (2009) Improved Algorithm for Tolerance Allocation Based on Monte Carlo Simulation and Discrete Optimization. Computers E Industrial Engineering 56(4):1402-1413.

[324] Wynn DC, Grebici K, Clarkson PJ (2011) Modelling the Evolution of Uncertainty Levels During Design. International Journal of Interactive Design and Manufacturing 5(3):187-202.

[325] Yao W, Chen X, Luo W, van Tooren M, Guo J (2011) Review of UncertaintyBased Multidisciplinary Design Optimization Methods for Aerospace Vehicles. Progress in Aerospace Sciences 47(6):450-479.

[326] Zeithaml VA (1988) Consumer Perceptions of Price, Quality, and Value: A Means-End Model and Synthesis of Evidence. The Journal of marketing 2-22.

[328] Zhang H, Cao Y, Wei Y, Yang J (2013) A Concurrent Design Method for Functional Tolerance and Structure Based on the Principle of Decomposition and Reconstitution. Procedia CIRP 10:194-202.

[329] Zhang Y, Li Z, Xu L, Wang J (2011) A New Method for Automatic Synthesis of Tolerances for Complex Assemblies Based on Polychromatic Sets. Enterprise Information Systems 5(3):337-358.

[330] Zhang Y, Li Z, Gao J, Hong J (2011) New Reasoning Algorithm for Assembly Tolerance Specifications and Corresponding Tolerance Zone Types. ComputerAided Design 43(12):1606-1628.

[331] Zhong Y, Qin Y, Huang M, Lu W, Chang L (2014) Constructing a Meta-Model for Assembly Tolerance Types with a Description Logic Based Approach. Computer-Aided Design 48:1-16.

[332] Zhong Y, Qin Y, Huang M, Lu W, Gao W, Du Y (2013) Automatically Generating Assembly Tolerance Types with an Ontology-Based Approach. ComputerAided Design 45(11):1253-1275.

[333] Zhou S, Huang Q, Shi J (2003) State Space Modeling of Dimensional Variation Propagation in Multistage Machining Process Using Differential Motion Vectors. IEEE Transactions on Robotics and Automation 19(2):296-309.

[334] Zhu Z, Anwer N, Mathieu L (2017) Deviation Modeling and Shape Transformation in Design for Additive Manufacturing. 27th CIRP Design Conference 2017, 10-12 May 2017, Cranfield, UK.

[335] Zhu Z, Keimasi S, Anwer N, Mathieu L, Qiao L (2016) Review of Shape Deviation Modelling for Additive Manufacturing. International Joint Conference on Mechanics, Design Engineering E Advanced Manufacturing (JCM 2016), 14-16 September 2016, Catania, Italy.

[336] Zou Z, Morse EP (2004) A Gap-Based Approach to Capture Fitting Conditions for Mechanical Assembly. Computer Aided Design 36:691-700. 